NBER WORKING PAPER SERIES

\title{
DEADLY DISCRIMINATION: \\ IMPLICATIONS OF "MISSING GIRLS" FOR WORKPLACE SAFETY
}

\author{
Zhibo Tan \\ Shang-Jin Wei \\ Xiaobo Zhang \\ Working Paper 28830 \\ http://www.nber.org/papers/w28830 \\ NATIONAL BUREAU OF ECONOMIC RESEARCH \\ 1050 Massachusetts Avenue \\ Cambridge, MA 02138 \\ May 2021
}

We thank an editor and three referees for helpful comments. All remaining errors are our responsibilities. The views expressed herein are those of the authors and do not necessarily reflect the views of the National Bureau of Economic Research.

NBER working papers are circulated for discussion and comment purposes. They have not been peer-reviewed or been subject to the review by the NBER Board of Directors that accompanies official NBER publications.

(C) 2021 by Zhibo Tan, Shang-Jin Wei, and Xiaobo Zhang. All rights reserved. Short sections of text, not to exceed two paragraphs, may be quoted without explicit permission provided that full credit, including $\odot$ notice, is given to the source. 
Deadly Discrimination: Implications of "Missing Girls" for Workplace Safety

Zhibo Tan, Shang-Jin Wei, and Xiaobo Zhang

NBER Working Paper No. 28830

May 2021

JEL No. J16,O1

\begin{abstract}
$\underline{\text { ABSTRACT }}$
We examine an indirect but potentially deadly consequence of the "missing girls" phenomenon. A shortage of brides causes many parents with sons of marriageable age to work harder and seek higher-paying but potentially dangerous jobs. In response, employers invest less in workplace safety, which in turn increases work-related mortality. Drawing from a broad range of data sets and taking advantage of large regional and temporal variations in sex ratios in China, we demonstrate that in areas with a more severe shortage of young women, the parents with unmarried sons suffer a significantly higher incidence of accidental injuries and workplace deaths.

Zhibo Tan

International Monetary Fund

700 19th Street NW

Washington, DC 20431

ztan@imf.org

Shang-Jin Wei

Graduate School of Business

Columbia University

Uris Hall 619

3022 Broadway

New York, NY 10027-6902

and NBER

shangjin.wei@columbia.edu

Xiaobo Zhang

National School of Development

Peking University and

International Food Policy Research Institute

2033 K Street, NW

Washington, DC 20006

x.zhang@nsd.pku.edu.cn
\end{abstract}




\section{Introduction}

In the absence of gender discrimination and sex-selective abortions, millions more girls would have been born and raised in countries such as China, India, Vietnam, and the Republic of Korea. The "missing girls" phenomenon is a deadly consequence of gender discrimination and has been well-studied by Sen (1992) and others. In this paper, we examine an indirect but also potentially deadly consequence of "missing girls" on parents with sons of marriageable age. Our hypothesis can be stated as follows: due to unnaturally low female-to-male ratios at birth, the subsequent shortage of potential brides induces many parents with sons of marriageable age to work harder and seek higher-paying but riskier jobs to accumulate wealth and improve their sons' attractiveness in the marriage market. ${ }^{1}$ In response, employers may invest less in workplace safety, which in turn will cause more injuries and deaths at workplaces in general. Our paper documents such a negative spillover effect of discrimination against girls (on top of other welfare losses associated with discrimination), which parents who terminate the life of an unborn girl did not take into account in the first place. As far as we know, this is the first paper that investigates this effect.

The deadly effect is sizable. In the decade between 2003 and 2013, despite rapid income growth, the mortality rate among Chinese men ages 41 to 60 increased by 12 percent. $^{2}$ Our paper finds that an increased sex ratio imbalance in the young cohort is associated with rising mortality of the parental cohort, particularly the mortality rate of adult men. The emerging body of literature on the economic impact of a sex ratio imbalance generally shows that young men or parents with sons will exert more work effort and take more risks to accumulate wealth and increase their (or their sons') attractiveness in the marriage market when facing male-biased sex ratios. ${ }^{3}$ However, the extra work effort and risk-taking behavior have come at a cost of higher mortality. Our paper contributes to the literature on the consequences of a sex ratio imbalance by highlighting an unintended deadly consequence. ${ }^{4}$

\footnotetext{
${ }^{1}$ For those families with a son that also violate the family planning policy, they may need to work even harder to pay a penalty for going over the birth quota.

2 "Why Chinese Men are Dying Despite Rising Income," The Wall Street Journal, February 25, 2017.

3 See Angrist (2002), Chiappori et al. (2002), Lafortune (2013), Abramitzky et al. (2011), Wei and Zhang (2011a; 2011b, Edlund et al. (2013), Bethmann and Kvasnicka (2013), Chang and Zhang (2015) ), and Wei et al. (2017).

4 A few papers have shown that a rising gender imbalance may also bring about some social ills. For instance, Edlund et al. (2013) reveal that increasing sex ratios may account for up to one-seventh of the overall rise in crime in China. Tucker et al. (2005) and South and Trent (2010) find that imbalanced sex ratios increase sexually transmitted infections through the channel of sexual behavior.
} 
Our paper speaks to the emerging body of literature on the economics of mortality. Case and Deaton (2015) find a rising midlife mortality rate among the middle-aged, white, non-Hispanic population in the United States between 1999 and 2013 in the face of growing competition associated with globalization. By analyzing publicly listed companies in China, Fisman and Wang (2015) show that politically connected firms have a higher likelihood of workplace deaths than nonconnected ones. However, this channel alone cannot explain why China's work-related death rate is much higher than that in most other developing countries, where politically connected firms are generally prevalent. Our paper offers a new explanation for China's high work-related mortality rate: the pressure to accumulate wealth in the face of a marriage market squeeze causes workers to work harder and take more risks, while employers may underinvest in workplace safety in response.

Our paper is also related to the literature on workplace safety and accidental deaths. Work-related deaths rank among the top 10 leading causes of mortality around the world, claiming around 1.1 million lives every year. The problem is particularly serious in China. In 2000, for every million tons of coal produced, 5.9 workers died in China. This mortality rate in coal production was 195 times higher than the level in the United States and nearly 13 times higher than the rate in India, whose gross domestic product (GDP) per capita was only half of that in China. ${ }^{5}$

The literature on accidental deaths focuses on environmental causes (Howland and Hingson, 1987a, 1987b; Blake et al., 1988; Myers et al., 1991; O’Loughlin et al., 1992; Fuller, 2000) or personal factors (Agnew and Suruda, 1993; Fuller, 2000; Lord and Dayhew, 2001; Dong et al., 2012). Although stress in general is listed as an important risk factor of health

5 Sources: China State Administration of Coal Mine Safety Bulletin (1990-2010); United States Mine Safety and Health Administration Bulletin (1990-2010); and BP Statistical Review of World Energy (1990-2010). In response to a series of large, deadly coal mine accidents, the state greatly tightened safety regulations in the 2000s, which may have resulted in the sharp drop in the death rate among Chinese coal mines from 2000 onward. Despite the progress, the death rate in Chinese coal mines was still as high as 15 times that in the United States and three times of that in India in 2010. In 2005, the number of coal mine deaths was 5,491 in China (Source: National Mine Safety Administration of China), while in the United States the number was only 23 (Source: Mine Safety and Health Administration, Department of Labor of the United States). Total employment in the coal mining industry was 4.45 million in China (Source: China Statistical Yearbook), but this number includes not only coal miners, but also many supporting staff (such as an accountant in a coal mining firm). There were 116,436 miners in the United States (Source: Mine Safety and Health Administration, Department of Labor of the United States). By these (imperfect) statistics, the number of deaths per million workers in China was 1,234, much higher than that in the United States (198). 
outcomes in the medical literature, few studies have examined the specific impact of competitive pressure on stress-related accidental deaths. Furthermore, none of the above studies traces the causes of accidental deaths to discrimination against girls or sex ratio imbalances.

We chose China for our empirical analysis for three reasons. First, while an unbalanced sex ratio in the premarital cohort has been observed in many economies, China has one of the most skewed sex ratios. China's rising sex ratio imbalance is caused by a combination of the one-child policy introduced in the late 1970s, the spread of ultrasound gender-identification technology, and a son-preference culture (Li and Zheng, 2009; Bulte et al., 2011). Until 2013, China had adopted a stringent one-child policy. Couples were only allowed to have one child except when both parents were only children, at least one parent was a member of an officially recognized ethnic minority, or the first child was a girl or disabled in rural areas. The sex ratio at birth increased from a normal level in the late 1980s to about 118 boys per 100 girls in 2010. In 2013, the Chinese government loosened the one-child policy by allowing married couples with one parent being an only child to have two children. In 2015, the policy was further loosened by allowing any couple to have two children.

Second, the family planning policy in China was unevenly enforced across regions, resulting in large regional variation in the sex ratio. The sex ratio of the premarital cohort (proxied by the age 10-19 cohort) ranges from 97 boys to 140 boys per 100 girls in our sample.

Third, China's marriage market is highly localized. Due to government restrictions on household registrations, internal mobility for the purpose of marriage is low in China. Nearly 90 percent of marriages take place between men and women from the same county (Wei and Zhang, 2011a). Most migrant workers only work in cities temporarily and get married in their hometowns. Therefore, the sex ratio of the premarital cohort at the county level can serve as a good proxy for the degree of the local marriage market squeeze.

China's rising gender imbalance, which varies greatly over time and across regions, provides a natural experiment to study the mortality cost of sex ratio imbalances. Our study focuses on parents' responses to their children's premarital sex ratios. China's culture has a strong preference for sons. In rural areas, parents normally live with their adult son's family and depend on them for elderly care. Therefore, it is crucial for parents to ensure that their sons get married. Moreover, in rural areas, it is a cultural norm for families with sons to build a house for marriage (Wei et al., 2017). Building a house is costly, inducing parents with a son to work hard and save diligently. With a shortage of brides, parents with a son work even harder and save even more. 
Normally jobs that carry more risk pay better. Thereby, the sex ratio imbalance induces parents with a son to seek more risks.

To build our case, we marshal empirical evidence from multiple data sources and organize it in two steps. First, we establish the fact that the work-related disability rate and accidental death rate are significantly higher among the cohort of parents in regions with a more skewed sex ratio (i.e., with a greater shortage of young women) in the premarital cohort than in regions with more balanced sex ratios. In terms of the economic effect, an increase in the sex ratio by one standard deviation in the sample elevates the accidental death rate of the parents' cohort by 0.16 standard deviation. By our estimation, the sex ratio imbalance plays an economically important role in driving up China's accidental deaths.

Second, we explore the mechanisms linking sex ratios and accidental death rates from the perspectives of employees and employers. On the employee side, we investigate an interaction effect: parents with unmarried sons in regions with a higher male-to-female ratio in the premarital cohort spend more time working outside their hometowns and take more dangerous jobs. At the same time, families with unmarried daughters do not exhibit a similar tendency. Since working extended hours and participating in dangerous jobs are risk factors for accidental deaths, we treat these patterns as additional evidence that the "missing girls" phenomenon induces riskier behavior that may be physically harmful to the workers.

On the employer side, we show that employers compromise workplace safety when potential employees have weakened bargaining power in regions with more premarital-age men than women. On the one hand, a significantly lower proportion of trade unions set up specialized committees in charge of workplace safety in regions with higher male-to-female ratios. ${ }^{6}$ On the other hand, companies in regions with a more skewed sex ratio are less likely to provide work-related injury insurance coverage, which is a critical facet of employers' investment in workplace safety.

The rest of the paper is organized as follows. In Section 2, we introduce our data and present descriptive statistics for the key variables. Section 3 uncovers the positive correlation between the local sex ratio in the child cohort and work-related injuries in the parental cohort. Section 4 presents more evidence of the causal effect on work-related accidental deaths. Section

6 As of 2011, 90 percent of the firms in China had established trade unions. 
5 shows more robustness checks on the main findings. Section 6 explores the underlying mechanisms. Section 7 concludes.

\section{Data and Descriptive Statistics}

The major outcome variables in the following analyses include work-related disability, accidental deaths due to fire or falls (mostly related to work), working outside the hometown, taking risky jobs, and employers' investment in workplace safety. The data sources are listed in Table 1. A detailed description of these variables and the data sets is provided in Online Appendix A. This section mainly describes sex ratios and accidental deaths due to fires or falls.

[Table 1 about here]

\subsection{Sex ratios}

Since our key outcome variable, accidental death, from China's National Disease Surveillance Points System (NDSPS) data set, is only available for 1991-2000, it is too early to observe the negative impact on the only-child generation born after 1979. Our paper focuses on the parental response to the marriage market squeeze among their children's cohort (which may underestimate the total effect because sons themselves may take risky jobs in high sex ratio settings when they grow up).

In the main analysis, we construct the average sex ratio of children for the age 25-39 parent cohort. Specifically, we first calculate, for each province, the probability of giving birth to the first child for adults of a given age using the 1990 population census. ${ }^{7}$ Second, we compute the sex ratio at birth by birth year at the county level. Third, we combine the above information to derive the average sex ratio of the children of parents in the age 25-39 cohort in each county, with the child sex ratio weighted across birth years by the probability of having children in each birth year. For instance, a mother age 25 in 1995 faces the following sex ratio of children: (the probability of having children when 20 years old $) \times($ the sex ratio of children born in 1990)+(the probability of having children when 21 years old) $\times$ (the sex ratio of children born in $1991)+\ldots+($ the probability of having children when 25 years old $) \times($ the sex ratio of children

\footnotetext{
7 We also calculate the probability at the county level and find that the results on the sex ratio remain similar. Due to space limits, we only report the results based on the probability at the province level.
} 
born in 1995). Using this method, we can calculate the child sex ratio for the age $25-39$ cohort in each county during 1991-2000.

As a robustness check, we also employ a simpler measure of the sex ratio of children in the age 10-19 cohort, inferred from the 1 percent sample of the 1990 census. ${ }^{8}$ When analyzing outcome variables (working outside the hometown and taking risky jobs) from the China Family Panel Studies (CFPS) 2010 survey, we use the sex ratio of the age 10-19 cohort inferred from the age 0-9 cohort in the China Population Census 2000. The youngest cohort in 2000 reached age 10 by 2010 . Our main results are robust to these two ways of measuring the child sex ratio.

\subsection{Work-related disability and accidental deaths}

The data on individual-level work-related injuries come from the Second China National Sample Survey on Disability (shortened below as National Disability Survey), which was conducted in 2006 jointly by the National Bureau of Statistics, the Ministry of Civil Affairs, and the China Disabled Persons' Federation. ${ }^{9}$

The survey includes information on respondents' basic demographic characteristics and their economic, social, and disability statuses. The demographic characteristics include individuals' age, gender, marital status, family size, and address. Economic and social statuses refer to level of education and personal income, respectively. For those identified as disabled, disability information includes disability status, severity, and pathogenic causes. Of particular interest to us is physical disability caused by work-related injuries.

The data on deaths come from the NDSPS, which includes all deaths (with exhaustive information on causes of death) in 145 sites. The sample was chosen to be nationally representative during 1991-2000 so that it captures China's variation in wealth and geographic dispersion. Several studies have used and described this data set (Ebenstein, 2012; Chen et al., 2013). Death can be work related or not work related or from a combination of both sources. Unfortunately, the NDSPS does not formally separate the two. Instead, we use deaths caused by fires, flames, or accidental falls to proxy work-related deaths. In principle, these deaths may be

\footnotetext{
${ }^{8}$ Using the 2000 population census data may result in measurement errors because the difference in gender-specific mortality rates across age cohorts in previous years $(1991-2000)$ would affect sex ratios observed in 2000.

9 For details about the survey, see Appendix A and Documentation of the Second China National Sample Survey on Disability (Office of the Second China National Sample Survey on Disability, 2007).
} 
caused by a combination of workplace and household sources. While we focus on parents in the age 25-39 cohort, the majority of falls at home usually occur among older people. According to the NDSPS 2013, the latest year for which we can obtain information about where falls happen at the national level, among people ages 65 years and older, about 80 percent of accidental falls happen at home or in old-age care homes. By comparison, among people ages 25-39, only 19 percent of falls happen at home. For the young cohort, accidental falls at home, even if they occur, are also less likely to be fatal. In comparison, falls at the workplace, such as a coal mine or a construction site, are much more dangerous. Furthermore, as shown in the recruitment advertisements for mine workers, ${ }^{10}$ most of the jobs require applicants who are younger than age 40. For these reasons, it seems sensible to associate regional variations in death by accidental falls to the variations in lethal workplace accidents.

To obtain further verification, we gathered the records on work-related deaths from the website of the State Administration of Work Safety (SAWS). ${ }^{11}$ We aggregate the original data at the company level to the provincial level and compare them with the number of deaths due to fires, flames, or accidental falls at the provincial level as reported in the NDSPS data. The correlation coefficient between the two series in 2000 is 0.52 , statistically significant at the 5 percent level. $^{12}$

2.3 Raw sex ratios, work-related disability, and accidental deaths

In Figure 1, the province-level rate of disability caused by work-related injuries, conditioning on the log of GDP per capita, is plotted against the local sex ratio of the premarital cohort. The disability rate is the number of disabled people whose disability was caused by work-related injuries divided by the average number of workers (unit: 1/100,000) in 2006. The premarital sex ratio is proxied by the sex ratio of the age 10-19 cohort in 2006 and is deduced from the age 4-13 cohort from the 2000 population census. We see a strong positive association between the local premarital sex ratio and the local work-related disability rate.

\footnotetext{
${ }_{10}$ For instance, http://www.pinlue.com/article/2019/06/2802/489266141343.html.

${ }^{11} \mathrm{http}: / /$ media.chinasafety.gov.cn:8090/iSystem/shigumain.jsp. As an example, an entry may read: “At around twelve o'clock on June 8th, the scaffold of Longshan Coke Company in the city of Xuzhou (Jiangsu province) collapsed and three men died."

${ }^{12}$ It is the first year that records from the State Administration of Work Safety became available. We use coal mine accidents as an example to illustrate the relative importance of deaths caused by fires, flames, or accidental falls. According to the data compiled from SAWS, fires caused by gas explosions and combustion account for $56.8 \%$ of deaths from coal mine accidents, while roofs falling and caving in due to coal or gas outburst account for $39.2 \%$ of deaths from coal mine accidents.
} 
[Figure 1 about here]

Figure 2 depicts the evolution of the sex ratio and work-related death rate at the national level over 1976-2003. ${ }^{13}$ The sex ratio variable is defined as the sex ratio at birth 20 years earlier, and the work-related death rate is computed as the number of deaths caused by work-related accidents divided by the average number of workers in a certain period (unit: 1/1,000,000), which is available from various issues of China's Work Safety Yearbook and the China Statistical Yearbook. To eliminate the effects of time trend, we rescale the two variables by subtracting the mean and dividing by the standard deviation. Figure 2 reveals that both variables move in sync for most of the period except for the late 1990s. ${ }^{14}$ Overall, the time trend of work-related deaths largely mirrors the trend for the sex ratio.

[Figure 2 about here]

Figure 3 plots the proportion of each province's work-related deaths in national total work-related deaths conditioning on the log of GDP per capita versus the sex ratio at the provincial level. Visually, the share of work-related deaths is higher in provinces with more skewed sex ratios.

[Figure 3 about here]

Table 2 compares the key outcome variable, the death rate due to work-related accidents, in high and low sex ratio regions. We calculate county-level accidental death rates (per 100,000 people) for the parents' cohort from the NDSPS data set. With the sample standard deviation being 12.5 deaths per 100,000 people, compared with a mean of 8.5 , the death rate exhibits wide dispersion. The average accidental death rate in the high sex ratio regions (10.55) is greater than that in the low sex ratio regions (6.54), and the difference is statistically significant.

[Table 2 about here]

\footnotetext{
13 The choice of this time span is due to data availability and the consistency of definition of work-related deaths.

14 A blip in the accidental death rate in the 1990s is likely associated with the massive privatization program that converted most of the smaller state-owned enterprises, including coal mines, into private enterprises, which might be less safety conscious.
} 


\section{Sex Ratios and Work-Related Disability}

As there are more work-related injuries than deaths, we first examine patterns of work-related disability.

$$
y_{i}=\beta_{1} \text { sexratio }_{i}+\beta_{2} I_{i}+\beta_{3} C_{i}+\varepsilon_{i} .
$$

In equation (1), the dependent variable, $y_{i}$, is an indicator variable for whether a person is disabled due to a work-related injury. The indicator takes the value zero if the person has a non-work-related disability. The sex ratio of the premarital cohort is the variable of interest. $I_{i}$ is a vector of individual-level characteristics, including gender, age, ethnicity, marital status, years of schooling, and occupation. $C_{i}$ are county-level controls, such as the total size of the cohort population (in log), share of prime-age population, and regional dummy variables. While we report the ordinary least squares (OLS) results in Table 3, we also implemented probit and logit regressions, which yielded similar results.

We restrict the regression sample to adults ages 25 to 39 in rural areas. ${ }^{15}$ As the dependent variable is for 2006, we calculate the sex ratio of the age 10-19 cohort based on the age 4-13 cohort in the 2000 population census. According to the results in column (1) in Table 3, if the local sex ratio increased by 10 basis points, the work-related disability rate would go up by 1.184 percent $(1.184 * 10 / 1000)$, which is about 22 percent of the mean disability rate $(5.41$ percent).

Because we are using the national disability database, the regression sample includes only individuals with work-related or non-work-related disabilities. Following Ebenstein (2012), we construct a county disability rate for 2006 (the number of workers physically disabled due to work injuries divided by the average number of workers; unit: 1/100,000) and regress it on the county-level sex ratio tabulated from the 2000 census. Column (2) in Table 3 presents the OLS estimates at the county level. Since some counties report zero values, we also run a Tobit regression as a robustness check in column (3). The coefficient for the sex ratio variable is significant and positive in columns (2) and (3). The increasing sex ratio imbalance is associated with a higher incidence of work-related disability. Based on column (2) in Table 3, a rise in the

\footnotetext{
15 We also tried the cohort 25-44. The main results remain the same. However, there is a slight chance that some people may become grandparents after age 40 years in rural areas.
} 
sex ratio by 10 percentage points would increase the work-related disability rate by 13.8 per $100,000(1.38 * 10)$, or 12.54 percent of the mean value.

[Table 3 about here]

\section{Sex Ratios and Accidental Deaths}

\subsection{Baseline results}

We construct a pseudo cohort-county-year panel by calculating the incidence of death by type of accident in each age cohort during 1991-2000. We use the corresponding total cohort population in a county to compute the death rates by cause. To be concrete, the specification is shown in equation (2). $y_{\text {cit }}$ represents the death rate of cohort $c$ in location $i$ in year $t$, and sex ratio $_{\text {cit }}$ corresponds to the child sex ratio faced by cohort $\mathrm{c}$ in the same location and year. We control for cohort, region, and year fixed effects, that is, $\alpha_{c}, \mu_{r}$, and $\eta_{t}$, respectively, in the pseudo-panel analysis.

$$
y_{c i t}=\text { sexratio }_{c i t}+\alpha_{c}+\mu_{r}+\eta_{t}+\varepsilon_{c r t}
$$

Table 4 summarizes the main results. ${ }^{16}$ Column (1) presents the OLS regression results on the death rate caused by fire or fall accidents in the age 25-39 cohort. The coefficient for the child sex ratio variable is 0.358 , significant at the 5 percent level. By comparison, in column (2), with the outcome variable being the combined death rate of the top three (non-work-related) causes of death (cerebrovascular disease, other respiratory system diseases, and malignant neoplasm of digestive organs and peritoneum), the coefficient for the sex ratio variable is insignificant.

\section{[Table 4 about here]}

In columns (1) and (2) in Table 5, we separately regress death rates for male and female adults, respectively, on the local child sex ratio. The coefficient on the sex ratio is much larger for male adults (0.576 in column (1)) than for females (0.153 in column (2)), and the difference

\footnotetext{
${ }^{16} \mathrm{We}$ also try Tobit regressions (with lower limit set at 0 ) controlling for cohort, regional, and year fixed effects since many cohort-county pairs' death incidence is 0 , although such models are subject to the incidental parameter problem. According to Greene (2004), the estimation of the slope of the fixed effects Tobit model, but not of the variance, is consistent. To examine the influence of outliers, we also exclude observations in the upper 5 percentiles as an additional robustness check. In these exercises, the results for sex ratio are similar.
} 
is statistically significant (see the interaction term in column (3)). In other words, adult death rates due to accidental falls or fires are higher in regions with a higher sex ratio, and this is especially true for adult males.

[Table 5 about here]

\subsection{Instrumental variable approach}

There may be concern about possible endogeneity of the sex ratio variable. In particular, parents with a son could be different from parents with a daughter in a way that covaries with the county-level sex ratio. To check this out, we compare families whose first child is a son and whose first child is a daughter in high and low sex ratio counties in Table D1, ${ }^{17}$ using CFPS survey data. As shown in the table, we see no significant differences for household head's age or education level in high and low sex ratio regions.

As a husband's income increases, his bargaining power in the household goes up, and he thereby has greater leverage to push his wife to have a sex selective abortion if he has a strong son preference. Regions with a stronger son preference can simultaneously see a higher sex ratio at birth and a stronger willingness by adult men to take riskier jobs to obtain the necessary bargaining power at home to push for abortion of girls. This story would predict that male adults not only earn more than females, but the gap in pay rises with the local sex ratio. We compute the log wage differential between husbands and wives for the age 25-39 cohort using the 20051 percent population census. We find that the wage differential is essentially uncorrelated with the local sex ratio at birth in 2005 (with a t-value of 0.32), largely dismissing the concern.

There may be other types of endogeneity problems, such as omitted variables or measurement errors. To address these potential problems, we employ the instrumental variable (IV) approach. Our choice of IVs, motivated by the family planning policy in China, is as follows. A key determinant of the sex ratio imbalance is the strict family planning policy introduced at the beginning of the 1980s (Hesketh et al., 2005; Bulte et al., 2011; Li et al., 2011). ${ }^{18}$ Whereas the goals of family planning are national, the enforcement, especially the fines

\footnotetext{
17 Since whether a family has a son is the consequence of sex-selective abortions, we use the first-born gender to do such comparison.

${ }^{18} \mathrm{Li}$ et al. (2011) find that enforcement of the one-child policy accounts for about $94 \%, 57 \%$, and $54 \%$ of the total increase in sex ratios during the 1980s, 1990s, and 2001-2005.
} 
for violating birth quotas, are set by local governments. Some local governments provide a bonus to those families who observed the birth quota, which is typically distributed monthly after the father reaches age 60 or the mother reaches age 55. Logically, parents in regions with a greater penalty for violating birth quotas or a lower bonus for staying with the quota would have a stronger incentive to engage in sex selective abortion. As a result, the sex ratio would be more male biased in such regions. Importantly, the monetary values of the penalties or bonuses are determined by the local leaders at the time when the children are born, rather than at the time when an accidental fall or fire occurs. Local leaders also tend to be rotated around the country, with a median tenure of five years. So the local leaders who set the penalties and bonuses are unlikely to be the same ones during our sample period. In other words, the instrumental variable is predetermined with respect to the economic and social situations of the sample period. Ebenstein (2010) coded two family planning policy variables, fertility fines and bonuses. He finds that the two policy variables are highly associated with the sex ratio at birth.

We first verify that the sex ratio at birth is strongly influenced by the fines and bonuses, as shown in Ebenstein (2010), by regressing the sex ratio of the children's cohort in our sample period on the family planning policies at the provincial level. We use the same data as Ebenstein (2010) to back out the average fine rate spanning the birth years of the sex ratio. As shown in columns (1) to (3) in Table D2, a higher fine (or a lower bonus) is associated with higher sex ratio of males to females, whether the penalty and the bonus are entered separately or jointly in the regressions. We also perform a falsification test following Ebenstein (2010). In column (4), we regress the sex ratio of the cohort that is 10 years older on the same set of family planning policy variables. Neither family planning policy variable is statistically significant in the regression of the sex ratio among the adjacent older cohort. The falsification test helps to rule out the concern that sex ratios were already higher for older cohorts in regions with a stricter one-child policy.

When China began the one-child policy, the main objective was to lower the fertility rate. It would be ideal to compare family planning policies in the early 1980s and work-related injuries or deaths prior to or around the same time. But such data are not available until 1991. As a second best, Figure 4 plots the one-child policy implemented in 1980 and accidental death rates in 1991 at the provincial level. There is little correlation between the two variables, suggesting 
that variation in the initial family policy has little to do with contemporaneous or prior accidental death rates or occupational danger. ${ }^{19}$

\section{[Figure 4 about here]}

We also carry out a balance test for key economic indicators between the regions where the monetary penalties for violating birth quotas are above and below the national median. The results are reported in Table 6 . We see no statistically significant differences between the two groups of regions in GDP per capita, education level, or industrial structure.

\section{[Table 6 about here]}

The right panel in Table 4 reports the two-stage least squares (2SLS) estimates following the same specifications in columns (1) and (2). ${ }^{20}$ The Hausman-Wu statistic is significant in all the regressions, rejecting the null hypothesis of no difference between OLS and 2SLS, suggesting that the sex ratio variable is endogenous. The significant Kleibergen-Paap Wald F Statistic (37.3) in the first-stage regression indicates that the instruments have predictive power on the sex ratio variable and we can easily reject the null of a weak instrument. The Hansen $\mathbf{J}$ statistic does not reject the null hypothesis of no correlation between the instrument and the error term in the main regression. The coefficient for the sex ratio variable in column (3) on the work-related accidental death rate is significantly positive at the 5 percent significance level. In comparison, column (4) shows that the sex ratio variable is insignificant in the 2SLS estimate on the death rate for the top three causes of death, which are not work related.

To bolster confidence in our story, we regress the death rate of each individual main cause on the sex ratio and check whether the coefficient for the sex ratio variable is larger in any

\footnotetext{
19 In 1991, children born in 1980 - whose parents were subject to penalties for higher order births in 1980-were only 11 years old and not old enough to enter the marriage market. Their parents' behavior at workplaces may not yet have responded to the competitive pressure in the marriage market. Instead, we expect to observe a stronger association between the sex ratio and accidental deaths for parents with older children in the later part of the sample. When we do similar regressions for individual years, we find that the correlations start to become positive and significant after 1994.

20 The family planning policies are mainly formulated at the provincial level but primarily implemented at the local level. As a robustness check, we use the interaction of the above two family planning policy variables with population density calculated from population censuses at the county level to proxy the degree of local implementation of the provincial family planning policy. In sparsely populated areas, such as remote mountainous villages, it is much harder for local officials to visit households and strictly enforce family planning policies than in more densely populated regions. It is reported that officials are more lenient in enforcing the family planning policy where the local population is sparsely distributed (Gu et al., 2007). In any case, we would expect to observe a more balanced sex ratio at birth in regions with low population density. The empirical results remain robust.
} 
of the regressions and has the same or higher significance level. We report the detailed results in Appendix Table D3 and summarize the results for the top three causes in Table 7. The top three causes of death are cerebrovascular diseases, other respiratory system diseases, and malignant neoplasms of digestive organs, which together account for 44.4 percent of all deaths. Importantly, as family medical history seems to play an important role in these causes, we deduce that workplace injuries are not as important for these illnesses (although we cannot rule this out completely). Table 7 shows that the sex ratio is not significantly associated with any of the top three causes of death.

\section{[Table 7 about here]}

Appendix Table D3 reports the 2SLS coefficients on the sex ratio in similar regressions for the top 50 causes of death, from NDSPS. ${ }^{21}$ It is apparent that most of the causes of death are not significantly associated with the sex ratio. The only cause of death that has a significantly positive relationship with the local sex ratio and has a coefficient that is larger than that for accidental falls or fires is open wound and injury to blood vessels. It is possible that some open wounds and injuries can originate from industrial accidents, which may be caused by increased marriage market competition. The positive relationship between the sex ratio and deaths from open wound and injury does not necessarily negate our hypothesis.

We conduct two falsification tests. In particular, in column (4) in Table 7, we replace the sex ratio of the children's cohort with the sex ratio of the cohort who are 10 years older. Since this is not the relevant children's cohort for the parents in the sample, we do not expect the sex ratio variable to be significant. Indeed, the coefficient is not statistically different from zero. In column (5), we use the sex ratio of the children who are 15 years older. We again see that deaths from accidental falls or fires and flames in the parent cohort do not react to the falsified sex ratio. This finding also bolsters confidence in our story.

\section{Robustness Checks}

We focus on the rural sample in our regression because the urban sample would include migrants from rural areas whose hometowns are unknown. In 1990, when the population census was taken, children ages 0 to 19 in rural areas were likely to stay where they were born with their grandparents or other relatives rather than moving with their parents to a city (Meng, 2012). One

\footnotetext{
21 Among the 50+ causes of death, accidental falls or fires and flames are usually ranked in the low 20s during 1991-1995 and
} high teens during 1996-2000. This is consistent with the more elevated sex ratio during 1996-2000 relative to the earlier period. 
reason is that the government restrictions known as the hukou system make it hard for rural children to obtain schooling or other social services in the cities. In any case, rural-to-urban migration did not take place on a large scale until the late 1990s. Even if some of the children grew up and worked in the cities themselves, the 2000 population census suggests that a majority of them got married in the counties where they were born. This means that the relative shortage of brides in local marriage markets is likely to be well captured by the data and our methodology.

To address the concern about the potential measurement error due to migration, we conduct a robustness check by restricting our geographic sample to the interior regions of China and the sample period before 1997. To test whether migration is a serious challenge to the baseline results, we restrict the regressions to the provinces and periods with a modest scale of migration. In sample 1, we drop the observations in Guangdong, Zhejiang, and Jiangsu, the three largest migration destinations. In sample 2, we drop the observations in Shandong, Jiangsu, Shanghai, Zhejiang, Fujian, and Guangdong, the rich, coastal areas of China. We repeat the main regressions using these subsamples. The main results, which are not reported to save space, are qualitatively the same.

We also checked the robustness of the results to different ways of constructing the sex ratio variable. For example, we can use the individual-level data from the 1 percent sample of the 1990 census to calculate the sex ratio of the age 10-19 cohort. All the major conclusions carry through (see Appendix Table D4). In addition, we used the sex ratio of the age 5-19 cohort. As the youngest children in this cohort were not born yet when the 1990 population census was conducted, we infer their sex ratio from the 2000 population census. The results based on the sex ratio of the age 5-19 cohort remain largely the same. They are not reported to save space.

Higher sex ratios can also lead to more crimes (Edlund et al., 2013). There may be some interest in whether some of the deaths by fires and flames came from arson instead of hard work and risk-taking economic behavior. We do not have data on arson. According to the China Law Yearbooks (1982-2005), the share of crimes in "other categories," to which arson belongs, ranged between 9 and 13 percent during 1981-2004. Thus, the incidence of arson is likely too small to make a dent in the total number of fire-related deaths. As a robustness check, we add the violent and property crime rate as a regressor. The sex ratio variable remains significant and positive, whereas the crime rate is insignificant. This suggests that the crime channel is unlikely to dominate the hard work and risk-taking channel. 
It is also possible that in areas with a more skewed sex ratio, male-intensive industries are developed to accommodate the excess of young men entering the labor force and at the same time, male-intensive industries might be riskier and have a higher injury rate. We use industry-level employment data from the United States in 2000 to classify industries in terms of their "intrinsic" gender composition, following a similar line of reasoning as Rajan and Zingales (1998). ${ }^{22}$ Figure B1 in Online Appendix B is a scatter plot of the injury rate and the ratio of male to female workers by industry. We do not see any significant relationship between the injury rate and the ratio of male to female workers by industry (with $t$ value of 0.01 ).

\section{Underlying Mechanisms}

We were unable to obtain information from the NDSPS data on whether the deceased had a son or a daughter. To overcome this shortcoming, we use the 2010 CFPS as a complement to delve into the underlying transmission channels.

We first examine the relationship between the sex ratio and the probability of working outside the hometown and present the regression results in Table $8 .^{23}$ We restrict our sample to nuclear families that had a child age 5 to 19 and household heads between ages 25 and 39 . The dependent variable is a dummy indicating whether the family has any member working outside the hometown. The key variable of interest is the sex ratio of the premarital age cohort. We can infer the sex ratio of the age 10-19 cohort in 2010 from the age 0-9 cohort in China's 2000 population census. The control variables include family size, household head's age, years of schooling, square of years of schooling, gender, ethnicity, a dummy for whether the household has a child between ages 10 and 14, and a dummy for whether the household has a child between ages 15 and 19.

To explore the difference between families with only a son and families having only a daughter, ${ }^{24}$ we first examine these two groups separately in columns (1) and (2) in Table 8. As shown in column (1), for families with only a son, the probability of working outside the

\footnotetext{
${ }^{22}$ Another reason for using the US data is that we do not have the industry-level work injury rate data for China.

${ }^{23}$ Use of probit or logit model yields similar results. To save space, we do not report these results separately.

${ }^{24}$ Since whether a family has a son is the consequence of sex-selective abortion, we use the first-born gender to divide the sample into two groups.
} 
hometown is significantly greater in a county with higher sex ratios. In sharp contrast, such a relationship is not significant, or even negative, for families with only a daughter, as shown in column (2). Column (3) presents the regression on the combined sample with an additional dummy variable for having a son and its interaction with the local sex ratio variable. The coefficient for the interaction term is 0.008 , statistically significant at the 5 percent level. In columns (4) to (6), we repeat the first three regressions by limiting the sample to families in which the mother is age 25 to 39, rather than according to the age of the household head. The results still hold. In a region with a more skewed sex ratio, families with only a son have a higher probability of working outside their hometown. These results imply that families with unmarried sons take actions in response to higher sex ratios to win a competitive advantage for their sons in the marriage market. Since working outside the hometown is a major method to earn higher income and increase bargaining power in the marriage market, parents with sons are more likely to choose to work away from home when facing more skewed local sex ratios.

[Table 8 about here]

Next, we turn to the links between sex ratios and time spent working outside the hometown and participation in risky jobs. In columns (1) to (3) in Table 9, the dependent variable is $\log (1+$ total months working outside hometown). The control variables are the same as those in the analysis of the probability of working outside the hometown. Since working outside the hometown is more relevant for rural residents, we mainly focus on the rural sample. ${ }^{25}$ The positive effect of the sex ratio on the number of months working outside the hometown mainly applies to families with only a son, rather than families with only a daughter.

[Table 9 about here]

Aside from working outside the hometown, taking part in risky jobs is another alternative approach to accumulate wealth, but doing so may result in a higher risk of accidental death. Risky jobs often offer higher income. After controlling for respondents' experience, age, gender, years of education, father's and mother's years of education, and county fixed effects, the mean difference of the parent cohort's income between a risky job and a non-risky job in rural areas is 3,307 yuan, which is significant at the 1 percent level. We investigate the connection between the sex ratio and participation in risky jobs in columns (4) to (6) in Table 9. The dependent variable

\footnotetext{
25 Because many families have no members working outside their hometown, as a robustness check, we also run Tobit
} regressions by setting the lower limit to zero and the results are qualitatively similar. 
equals 1 if any family member has a dangerous job and 0 otherwise. Dangerous jobs encompass firefighting, public security, mineral mining, well drilling, oil and gas exploration, construction, electricity supply, installation and debugging of electrical equipment, and operation of mechanical equipment. The control variables are the same as those in the analysis of working outside the hometown. Although the coefficient on the sex ratio in the subsample with only a son is not significant, in the subsample in which the only child is a daughter, the coefficient is significantly negative. That is, in a region with a higher sex ratio, families with only a daughter are less likely to engage in risky jobs. In the regression on the combined sample (column (6)), the coefficient for the interaction term between having a son and the local sex ratio is positive and statistically significant, indicating that families with only a son are more likely to take risky jobs than families with only a daughter, in response to skewed local sex ratios. ${ }^{26}$

Due to lack of work-related injury and death data at the industry level in China, our classification of dangerous jobs is somewhat ad hoc. We rely on data from the Chinese Household Income Project (CHIP) 2002 for additional evidence. The CHIP survey includes a few questions on respondents' working sector (Q209. mining, construction, and so forth), health condition, disability, and medical expenditure. We create a variable for ill health and compare it between high-risk and low-risk industries. It is defined as 1 if a respondent reports bad health or being disabled $(\mathrm{Q} 116=1)$, and 0 otherwise. We classify industries into high and low risk ones according to work-related injury rates in US industries. The industries with the top fatal injury rates (higher than the national rate) are agriculture, fishing, forestry and hunting, mining, quarrying, oil and gas extraction, construction, transportation, and warehousing. We define these industries as high-risk industries and other industries as low-risk ones. The ill-health ratio in the low-risk industries is 2.6 percent, compared with 3.4 percent in high-risk industries. The difference is significant at the 5 percent level.

We also examine the difference in the ratio of medical expenditure to income between high-risk and low-risk industries. We calculate the ratio of medical expenditure to income for each person and aggregate to the industry level (mean). The ratios of medical expenditure to income inferred from the CHIP data corresponding to high-risk and low-risk industries are 18.12 and 15.33 percent, respectively. They are statistically different at the 1 percent level. Overall, the

\footnotetext{
${ }^{26}$ We also focus the sample on nuclear families and the results remain robust. If we divide the sample into families with sons and families with only daughters, the empirical results continue to hold.
} 
evidence suggests that people working in high-risk sectors are more likely to report ill health and spend more on medical care than their counterparts in low-risk industries.

Imbalanced sex ratios affect not only employees, but also employers. When parents with sons are so eager to earn quick money and care less about working conditions in the wake of a competitive marriage market in the premarital cohort, employers may invest less in workplace safety. We next scrutinize whether employers compromise workplace safety in areas with more skewed sex ratios.

We first examine the share of trade unions that have set up labor protection, supervision, and inspection committees (LPSICs), which are dedicated committees of a trade union that are responsible for workplace safety issues. The key responsibility of such committees is to participate in the formulation and implementation of workplace safety measures. They convey workers' concerns and suggestions about safety and health in the workplace to upper management with the purpose of improving working conditions. The LPSICs are available at the province level. We include only the provinces covered by the CFPS 2010 for ease of comparison. ${ }^{27}$ The sex ratio of the age 10-19 cohort at the province level is calculated from the 2010 population census. All data on trade unions and committees are from the Chinese Trade Unions Statistics Yearbook 2012.

Figure C2 presents a scatter plot of the two variables conditional on the log of GDP per capita, indicating a clear negative relationship. That is, the higher the sex ratio is, the less is invested in workplace safety.

In addition to committees on workplace safety, trade unions may also establish "warm heart project" committees, which help employees cope with the economic difficulties in life. There are also labor legal supervision committees, which supervise the implementation of labor law in the workplace; technical cooperation committees, which encourage technical cooperation among employees to improve productivity and carry out technical contests to boost technical innovation and invention; and labor dispute mediation committees (LDMCs), which deal with the renewal, dissolution, termination, and continuation of labor contracts, the dismissal or resignation of staff and workers, labor rewards, insurance, working hours, rest and vacation, labor safety and sanitation, occupational training, and special protection for underage workers

${ }^{27}$ The results based on all provinces are similar. 
and female workers. LPSICs and LDMCs are more common than other types of committees. ${ }^{28}$ Although LDMCs cope with labor safety and sanitation problems as well, their role is mainly reflected in the field of renewal, dissolution, termination, and continuation of labor contracts, rather than safety-related issues. ${ }^{29}$

Since the above information is available only at the province level, the sample size is too small to carry out a robust regression analysis. As an alternative, we implement a placebo test to examine whether sex ratios are significantly connected with the share of LDMCs. Considering that LDMCs do not primarily deal with safety-related issues, we do not expect to observe a significantly negative pattern. Figure C3 confirms that this is indeed the case. Applying the same conditional plot for LMDCs in Figure C3, the fitted line is fairly flat and the $t$ value for sex ratios is only -0.07 .

Because work-related injury insurance is also an important facet of workers' rights and a critical investment that employers should make in workplace safety, we expect to see a negative impact of the sex ratio on work-related injury insurance coverage. We use the share of employees who are covered by work-related injury insurance as the dependent variable and carry out the analysis at the firm and county level (by averaging insurance coverage to the county level).

Table 10 shows the OLS and 2SLS regression results on sex ratios and work-related injury insurance coverage at the firm level. Column (1) starts with the most parsimonious regression including only the local sex ratio variable. The coefficient for the sex ratio variable is -0.014 , which is significant at the 1 percent level. In column (2), we add the share of total union members, female union members, and rural union members in total employees to the regression to separate the impacts of the strength and composition of unions on insurance coverage. The shares of female employees, rural employees, and grassroots employees on the board of directors and supervisors are also controlled, to take into consideration corporate governance factors. In addition, we control for the log of sales and other firm-level financial indicators, which are normalized with sales to isolate the influence of profits, liquidity, leverage, and expenses on

\footnotetext{
${ }^{28}$ In 2011, the average shares of trade unions that had set up LPSICs, "warm heart project" committees, labor legal supervision committees, technical cooperation committees, and LDMCs across provinces were, respectively, 24.17, 6.33, 18.80, 1.79, and 23.72 percent.

${ }^{29}$ In 2011, the average proportion of labor contract dispute cases in total cases handled by LDMCs across provinces was 57.4 percent, whereas the figure for labor safety and sanitation disputes was 2.17 percent. LDMCs coped with 5,866 safety cases nationally, whereas the figure for LPSICs was 59,207.
} 
insurance coverage. With these controls, the sex ratio variable barely changes and remains highly significant. In column (3), we further include industry, ownership, and province fixed effects. The coefficient changes slightly to -0.010 and is significant at the 1 percent level. That is, an increase in the sex ratio by one standard deviation will decrease the injury insurance coverage ratio by 8.6 percentage points. Since insurance coverage ratios are censored between 0 and 1 , we also try the Tobit model and the fractional model as well. The results are qualitatively similar.

Columns (4) to (6) present the 2SLS estimates corresponding to the OLS specifications in columns (1) to (3). The coefficient for the sex ratio variable is largely consistent with that in the OLS regressions in terms of sign and magnitude. The large first-stage F statistic and insignificant Hansen J statistic confirm the validity of the instruments used in 2SLS. Table 10 demonstrates that the results are robust to the inclusion of controls for firm-level characteristics, industry and owner type dummies, and province dummies. The coefficient for the sex ratio variable is negative and highly significant at the 1 percent level in all the regressions. That is, a region with a higher local sex ratio is less likely to provide work-related injury insurance coverage.

[Table 10 about here]

Apart from reluctance to provide work injury insurance coverage, firms may also invest less in other welfare programs, such as pension coverage, medical insurance coverage, and unemployment insurance coverage. As a robustness check, we repeat the regressions in Table 10 with pension, medical insurance, and unemployment insurance coverages separately as outcome variables. The results show that in regions with a more unbalanced premarital sex ratio, the pension, medical insurance, and unemployment insurance coverages are all significantly lower. This lends further support to our interpretation that workers' bargaining power is weaker in regions with higher sex ratios.

\section{Conclusions}

We explored the negative health consequences of "missing women" among the premarital age cohort on the parent cohort. We investigated whether and how greater male-to-female ratios of the premarital age cohort lead to a higher incidence of accidental deaths among the parent cohort. Empirical evidence based on five large data sets demonstrates that skewed male-to-female ratios among the young cohort increase the likelihood of work-related injuries and accidental deaths 
due to fires or falls among the parent cohort. To accumulate wealth and improve their sons' attractiveness in the marriage market, parents react to the imbalanced sex ratios by working harder and taking more risks, resulting in more deaths. Imbalanced sex ratios boost the probability of and time spent working outside the hometown as well as participation in risky jobs for families with sons, but not for families with only daughters. And employers invest less in workplace safety in regions with skewed sex ratios where more potential employees are willing to put up with dangerous working conditions. These findings shed some light on the puzzle of the rising midlife male mortality in China over the past decade.

Competitive pressure as a cause of work-related injury and accidental death has not been systematically explored in the literature. Our paper demonstrates that "missing women" have unintended deadly consequences for families with sons. Since the "missing women" problem is common in many other countries, including India, Vietnam, and until recently Korea, our research sheds light on the causes of work-related injury and deaths in these countries as well. 


\section{References}

Abramitzky, R., A. Delavande, and L. Vasconcelos. 2011. "Marrying Up: The Role of Sex Ratio in Assortative Matching." American Economic Journal: Applied Economics 3: 124-157.

Agnew, J., and A. J. Suruda. 1993. "Age and Fatal Work-Related Falls." Human Factors: The Journal of the Human Factors and Ergonomics Society 35(4): 731-736.

Angrist, J. 2002. "How Do Sex Ratios Affect Marriage and Labor Markets? Evidence from America's Second Generation.” Quarterly Journal of Economics 117(3): 997-1038.

Bethmann, D., and M. Kvasnicka. 2013. "World War II, Missing Men and out of Wedlock Childbearing." Economic Journal 123(567): 162-194.

Blake, A. J., K. Morgan, and M. J. Bendall. 1988. "Falls by Elderly People at Home: Prevalence and Associated Factors." Age and Aging 17(6): 365-372.

Bulte, E., N. Heerink, and X. Zhang. 2011. "China's One-Child Policy and "the Mystery of Missing Women': Ethnic Minorities and Male-Biased Sex Ratios." Oxford Bulletin of Economics and Statistics 73(1): 21-39.

Case, A., and A. Deaton. 2015. "Rising Morbidity and Mortality in Midlife among White Non-Hispanic Americans in the 21st Century." Proceedings of the National Academy of Sciences 112 (49): 15078-15083.

Chang, S., and X. Zhang. 2015. "Mating Competition and Entrepreneurship." Journal of Economic Behavior and Organization 116: 292-309.

Chen, Y., A. Ebenstein, M. Greenstone, and H. Li. 2013. "Evidence on the Impact of Sustained Exposure to Air Pollution from China's Huai River Policy." Proceedings of the National Academy of Sciences 110 (32): 12936-12941.

Chiappori, P.-A., B. Fortin, and G. Lacroix. 2002. "Marriage Market, Divorce Legislation, and Household Labor Supply.” Journal of Political Economy 110(1): 37-72.

Dong, X. S., X. Wang, and C. Daw. 2012. "Fatal Falls among Older Construction Workers." Human Factors: The Journal of the Human Factors and Ergonomics Society 54(3): 303-315. 
Ebenstein, A. 2010. "The 'Missing Girls' of China and the Unintended Consequences of the One Child Policy." Journal of Human Resources 45 (1): 87-114.

Ebenstein, A. 2012. "The Consequences of Industrialization: Evidence from Water Pollution and Digestive Cancers in China." Review of Economics and Statistics 94(1): 186-201. Edlund, L., H. Li, J. Yi, and J. Zhang. 2013. "Sex Ratios and Crime: Evidence from China.” Review of Economics and Statistics 95(5): 1520-1534.

Fisman, R., and Y. Wang. 2015. "The Mortality Cost of Political Connections." Review of Economic Studies 82 (4): 1346-1382.

Frank, R. H. 1985. “The Demand for Unobservable and Other Nonpositional Goods.” American Economic Review 75(1): 101-116.

Fuller, G. F. 2000. "Falls in the Elderly." American Family Physician 61(7): 2159-2168.

Greene, W. 2004. "Fixed Effects and Bias Due to the Incidental Parameters Problem in the Tobit Model." Econometric Reviews 23(2): 125-147.

Gu, B., F. Wang, Z. Guo, and E. Zhang. 2007. "China's Local and National Fertility Policies at the End of Twentieth Century." Population and Development Review 33 (1): 129-147.

Hesketh, T., L. Lu, and Z. Xing. 2005. "The Effect of China's One-Child Family Policy after 25 Years." The New England Journal of Medicine 353(11): 1171-1176.

Hopkins. E., and T. Kornienko. 2004. "Running to Keep in the Same Place: Consumer Choice as a Game of Status.” American Economic Review 94(4): 1085-1107.

Howland, J., and R. Hingson. 1987a. “Alcohol as a Risk Factor for Injury or Death Resulting from Accidental Falls: A Review of the Literature." Journal of Studies on Alcohol and Drugs 48(3): 212-219.

- 1987b. "Alcohol as a Risk Factor for Injuries or Death due to Fires and Burns: Review of the Literature." Public Health 102(5): 475-483.

Lafortune, J. 2013. "Making Yourself Attractive: Pre-Marital Investments and the Returns to Education in the Marriage Market." American Economic Journal: Applied Economics 5(2): $151-178$. 
Li, H., J. Yi, and J. Zhang. 2011. "Estimating the Effect of the One-child Policy on Sex Ratio Imbalance in China: Identification Based on the Difference-in-Differences." Demography 48(4): $1535-1557$.

Li, H., and H. Zheng. 2009. "Ultrasonography and Sex Ratios in China." Asian Economic Policy Review 4(1): 121-137.

Lord, S. R., and J. Dayhew. 2001. "Visual Risk Factors for Falls in Older People." Journal of the American Geriatrics Society 49(5): 508-515.

Meng, X. 2012. "Labor Market Outcomes and Reforms in China." Journal of Economic Perspectives 26(4): 75-102.

Myers, A. H., S. P. Baker, M. L. Van Natta, H. Abbey, and E. G. Robinson. 1991. "Risk Factors Associated with Falls and Injuries among Elderly Institutionalized Persons." American Journal of Epidemiology 133(11): 1179-1190.

O’Loughlin, J. L., Y. Robitaille, J.-F. Boivin, and S. Suissa. 1992. "Incidence of and Risk Factors for Falls and Injurious Falls among the Community-Dwelling Elderly." American Journal of Epidemiology 137(3): 342-354.

Office of the Second China National Sample Survey on Disability, 2007. Documentation of the Second China National Sample Survey on Disability. Beijing: China Statistical Press.

Rajan, R. G., and L. Zingales. 1998. "Financial Dependence and Growth.” American Economic Review 88(3): 559-586.

Sen, A. 1992. "Missing Women.” British Medical Journal 304(6827): 587-588.

South, S. J., and K. Trent. 2010. “Imbalanced Sex Ratios, Men's Sexual Behavior, and Risk of Sexually Transmitted Infection in China." Journal of Health and Social Behavior 51(4): 376-390.

Tucker, J. D., G. E. Henderson, T. F. Wang, Y. Y. Huang, W. Parish, S. M. Pan, X. S. Chen, and M. S. Cohen. 2005. "Surplus Men, Sex Work, and the Spread of HIV in China." AIDS 19(6): $539-547$. 
Wei, S.-J., and X. Zhang. 2011a. "The Competitive Saving Motive: Evidence from Rising Sex Ratios and Savings Rates in China." Journal of Political Economy 119(3): 511-564.

- 2011b. "Sex Ratios, Entrepreneurship, and Economic Growth in the People's Republic of China." NBER Working Paper 16800. National Bureau of Economic Research. Cambridge, MA.

Wei, S.-J., X. Zhang, and Y. Liu. 2017. "Home Ownership as Status Competition: Some Theory and Evidence.” Journal of Development Economics 127: 169-186. 


\section{Table 1-Data Sources}

\begin{tabular}{lll}
\hline Tables & \multicolumn{1}{c}{ Variables } & \multicolumn{1}{c}{ Data sources } \\
\hline Table 2 & Accidental death rates & National Disease Surveillance Points System (1991-2000) \\
& Sex ratios & $1 \%$ sample of China Population Census in 1990 and 2000 \\
& Disability due to work injury & China National Sample Survey on Disability (2006) \\
& Sex ratios and population variables & $1 \%$ sample of China Population Census 2000 \\
& All other variables & China National Sample Survey on Disability (2006) \\
Tables 4-7 & Accidental death rates & National Disease Surveillance Points System (1991-2000) \\
& Sex ratios and population variables & $1 \%$ sample of China Population Census in 1990 and 2000 \\
& GDP, education, industrial structure & Comprehensive Statistical Data and Materials on 50 Years of New China \\
& One child bonus & Ebenstein (2010) \\
& Premium for higher-order birth & Ebenstein (2010) \\
& All other variables & National Disease Surveillance Points System (1991-2000) \\
Tables 8-9 & Sex ratios & Tabulations of China Population Census 2000 at the county level \\
& One child bonus & Ebenstein (2010) \\
& Premium for higher-order birth & Ebenstein (2010) \\
& All other variables & China Family Panel Studies (2010) \\
Work-related insurance & All-China Federation of Trade Unions Survey (2009) \\
& Sex ratios & Tabulations of China Population Census 2000 at the county level \\
& One child bonus & Ebenstein (2010) \\
Premium for higher-order birth & Ebenstein (2010) \\
& Financial statement variables & Annual Survey of Industrial Firms (National Bureau of Statistics) \\
& All other variables & All-China Federation of Trade Unions Survey (2009) \\
\hline & &
\end{tabular}


Table 2-Summary Statistics of Key Variables

Whole sample

\begin{tabular}{|c|c|c|c|c|c|}
\hline & $\begin{array}{c}\text { Mean } \\
\text { (1) }\end{array}$ & $\begin{array}{c}\text { Standard deviation } \\
(2)\end{array}$ & $\begin{array}{c}\text { Mean } \\
\text { (3) }\end{array}$ & $\begin{array}{c}\text { Mean } \\
\text { (4) }\end{array}$ & $\begin{array}{c}\text { Mean difference } \\
(5)\end{array}$ \\
\hline Sex ratio of children's cohort & 108.31 & 5.78 & 101.18 & 118.95 & $-17.77 * * *$ \\
\hline Death rate due to accidents & 8.54 & 12.51 & 6.54 & 10.55 & $-4.01 * * *$ \\
\hline
\end{tabular}

Source: National Disease Surveillance Points System (1991-2000).

Note: Summary statistics for the county-cohort-year-level death rates for the age 25-39 cohort are presented in the table. Death rates due to accidents are defined as the number of deaths due to fire and flames and accidental falls per 100,000 people, based on the National Disease Surveillance Points System data set. The sex ratio variable is the weighted sum of the sex ratio of the children born in each year, with the weight equaling the probability of giving birth to the first child at each age. We use the median of the sex ratio in the full sample to divide the full sample into two subsamples. Below-/above-median refers to the subsample where the sex ratio is below/above the median of the sex ratio in the whole sample. The symbol $* * *$ indicates that we can reject the null hypothesis that the mean difference is 0 at the $1 \%$ significance level. 
Table 3-Sex Ratio and Disability Due to Work Injury

\begin{tabular}{|c|c|c|c|}
\hline & \multirow{2}{*}{$\begin{array}{c}\text { Individual level } \\
\text { OLS }\end{array}$} & \multicolumn{2}{|c|}{ County level } \\
\hline & & OLS & Tobit \\
\hline & (1) & (2) & (3) \\
\hline \multirow[t]{2}{*}{ Sex ratio of age $10-19$ cohort } & $1.184 * *$ & $1.380 * * *$ & $3.124 * * *$ \\
\hline & $(0.502)$ & $(0.519)$ & $(1.173)$ \\
\hline Observations & 626,272 & 733 & 733 \\
\hline Mean of dependent variable & $5.41 \%$ & $0.11 \%$ & $0.11 \%$ \\
\hline Standard deviation of dependent variable & $8.76 \%$ & $0.18 \%$ & $0.18 \%$ \\
\hline
\end{tabular}

Source: China National Sample Survey on Disability (2006).

Note: OLS = ordinary least squares. We have restricted the sample to respondents ages 25 to 39 and from rural areas. In the individual-level analysis, the sample encompasses the physically disabled people in the survey. The dependent variable equals 1 if the respondent is physically disabled due to work injury and 0 otherwise. We have controlled for the respondent's age, gender, education level, marital status, occupation, and province dummies. In the county-level analysis, the dependent variable is the disability rate due to work injury (number of workers physically disabled due to work injury divided by the average number of workers, unit: 1/100,000). The mean value in the individual-level and county-level regressions refers to the share of physically disabled people due to work injury in physically disabled people and the share of surveyed disabled people due to work injury in the total sample population. Since the denominator is different, the means of the dependent variable in columns (1) and (2) differ a lot. Considering that many counties have no people who are physically disabled due to work injury, we also report Tobit results, with the lower limit set at 0 in the county-level analysis. The sex ratio of the age 10-19 cohort refers to the male-to-female ratios among the age 4-13 cohort, inferred from the 2000 population census. For ease of exposition, in the individual-level analysis, we have rescaled our independent variables by dividing by 1,000. Robust standard errors clustered at the county level are in parentheses. The symbols $* * *, * *$, and * indicate statistical significance at the $1 \%, 5 \%$, and $10 \%$ levels, respectively. 
Table 4 —Sex Ratio and Accidental Death: Cohort-County-Year Regressions

\begin{tabular}{lcccc}
\hline & \multicolumn{2}{c}{ OLS } & \multicolumn{2}{c}{ 2SLS } \\
\cline { 2 - 5 } & Accidents & Top 3 causes & Accidents & Top 3 causes \\
& $(1)$ & $($ mean 58.5) & $($ mean 8.39) & $($ mean 58.5) \\
& $0.358^{* *}$ & $(2)$ & $(3)$ & $(4)$ \\
\hline Sex ratio of children & $(0.182)$ & $(1.164)$ & $(0.645)$ & 3.481 \\
F of the first stage & & & $37.3^{* * *}$ & $37.3^{* * *}$ \\
Hausman-Wu statistic & & & $5.04^{* * *}$ & $3.98^{* *}$ \\
Hansen J statistic & 1,980 & 1,980 & 2.05 & 2.01 \\
Observations & & 1,980 & 1,980 \\
Fraction of other causes of deaths having larger coefficient than accidental death at same or higher significance level: $1.9 \%$
\end{tabular}

Source: National Disease Surveillance Points System (1991-2000).

Note: OLS = ordinary least squares; 2 SLS $=$ two-stage least squares. Parents' cohort age is $25-39$. F of the first stage indicates the Kleibergen-Paap Wald F statistic in the first-stage regressions. The instrumental variables (IVs) for the sex ratio are fines for higher order birth in years of income $(\mathrm{F})$ and $\log$ of the amount of the one-child bonus (B). If we use F, B, log of population density (L), F $\times \mathrm{L}$, and $\mathrm{B} \times \mathrm{L}$ as IVs for sex ratio, or F, B, F×L, B $\times \mathrm{L}$ as IVs for sex ratio, the results are qualitatively similar. The dependent variable is death incidence. Accident indicates accidental deaths caused by fire and flames or accidental falls. As a placebo test, we look at the death rate for the top three causes of death (cerebrovascular disease, other respiratory system diseases, and malignant neoplasm of digestive organs and peritoneum all together). The sex ratio variable is the weighted sum of the sex ratio of the children born in each year, with the weight equaling the probability of giving birth to the first child at each age. We control for cohort, regional, and year dummies in all the regressions. We also control for the log of the cohort population in case of inaccuracy in death incidence due to small cohort size. The results for the sex ratios are similar. Robust standard errors clustered at the county level are in parentheses. *, **, and *** stand for significance level at $10 \%, 5 \%$ and $1 \%$, respectively. 


\section{Table 5-Gender Disparity in Accidental Deaths Due to Falls or Fires}

\begin{tabular}{lccc}
\hline & $\begin{array}{c}\text { Male death rate } \\
(1)\end{array}$ & $\begin{array}{c}\text { Female death rate } \\
(2)\end{array}$ & \multicolumn{2}{c}{ Death rate } \\
\cline { 2 - 3 } Male $\times$ sex ratio of children & & & $0.401^{* *}$ \\
& & & $(0.161)$ \\
Sex ratio of children & $0.576^{* * *}$ & $0.153^{* *}$ & $0.164^{* * *}$ \\
Male & $(0.162)$ & $(0.063)$ & $(0.060)$ \\
& & & $-0.339^{* *}$ \\
Observations & & & $(0.173)$ \\
\hline
\end{tabular}

Note: The table reports the county-cohort-year-level ordinary least squares regression results. The dependent variable is death rates for the age 25-39 cohort. Death rates are defined as the number of deaths due to accidental falls or fires and flames per 100,000 people, based on the National Disease Surveillance Points System data set. The sex ratio variable is the weighted sum of the sex ratio of the children born each year, with the weight equaling the probability of giving birth to the first child at each age. We control for cohort, regional, and year dummies in all the regressions. Robust standard errors clustered at the county level are in parentheses. $*$, **, and $* * *$ stand for significance level at $10 \%, 5 \%$ and $1 \%$, respectively. 


\section{Table 6-Balance Test of Key Variables}

\begin{tabular}{lccc}
\hline & High fines group & Low fines group & Difference \\
\hline Accidental death rate (1991) & 0.859 & 0.655 & 0.203 \\
& $(1.347)$ & $(0.769)$ & $(\mathrm{p}=0.628)$ \\
GDP per capita in RMB (yuan) & $2,279.07$ & $1,790.57$ & 488.502 \\
& $(1,671.58)$ & $(663.503)$ & $(\mathrm{p}=0.319)$ \\
Student enrollment number per 10,000 & 7.057 & 7.250 & -0.193 \\
persons in institutions of higher education & $(4.245)$ & $(4.46)$ & $(\mathrm{p}=0.908)$ \\
Employment share of secondary industry $(\%)$ & 22.933 & 22.741 & 0.192 \\
& $(14.049)$ & $(9.141)$ & $(\mathrm{p}=0.966)$ \\
Employment share of tertiary industry $(\%)$ & 20.158 & 17.777 & 2.381 \\
Share of secondary industry in GDP $(\%)$ & $(7.953)$ & $(4.795)$ & $(\mathrm{p}=0.346)$ \\
& 39.255 & 40.723 & -1.469 \\
Share of tertiary industry in GDP $(\%)$ & $(10.53)$ & $(7.299)$ & $(\mathrm{p}=0.672)$ \\
& 33.582 & 32.662 & 0.92 \\
\hline
\end{tabular}

Note: We use the median value of fines for higher order births in terms of yearly income in 1980 to divide the provinces into the high fines group (higher than the median) and low fines group (lower than the median). The table reports the mean value (the standard deviation is in parentheses) of the key variables in 1991 in these two groups. The last column reports the difference of the mean between these groups and its $\mathrm{p}$ value (in parentheses). 
Table 7-Placebo Tests: Cohort-County-Year Regressions

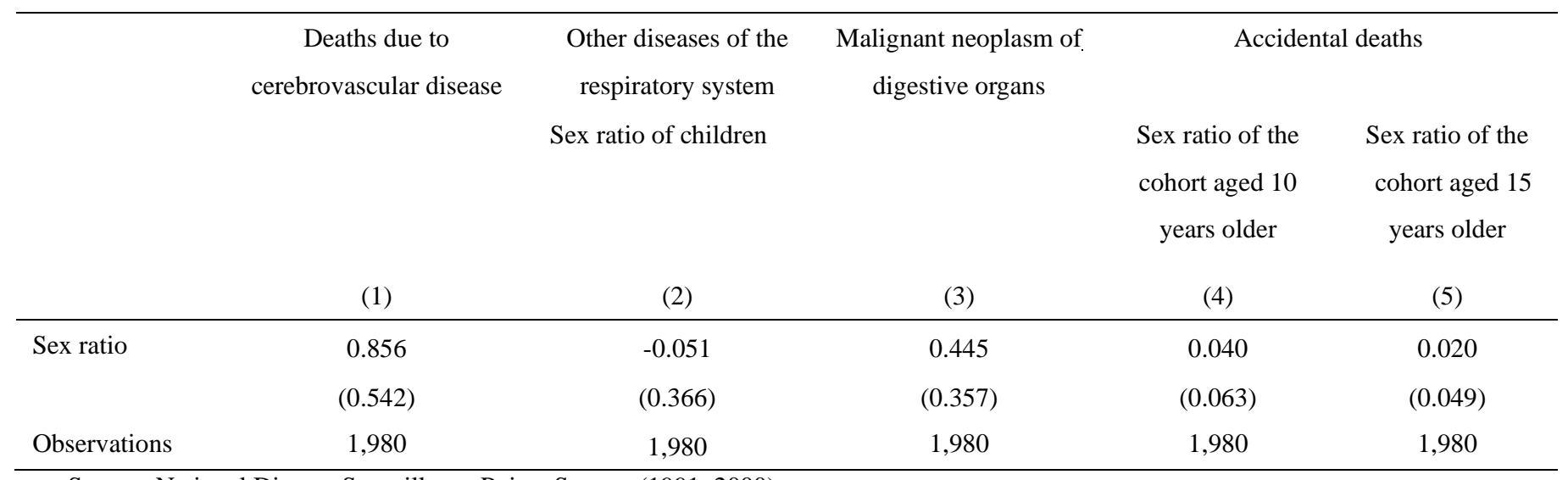

Source: National Disease Surveillance Points System (1991-2000).

Note: The table reports results using ordinary least squares regressions, which are conducted for the parents' cohort sample. The parents' cohort is ages 25-39. In columns (1) to (3), the dependent variables are the top three causes of death: cerebrovascular disease, other respiratory system diseases, and malignant neoplasm of digestive organs and peritoneum, respectively. In columns (4) and (5), the dependent variable is accidental death due to fire and flames or accidental falls. The child sex ratio is the weighted sum of the sex ratio of the children born each year, with the weight equaling the probability of giving birth to the first child at each age. The sex ratio of the age 10 (15) years older cohort is calculated for the parents' cohort. For example, for the age 25-29 parent cohort in 1998, sex ratio of the age 10 (15) years older cohort is the sex ratio of the age 35-39 (40-44) cohort in 1998 and is deduced from the sex ratio of the age 27-31 (32-36) cohort from the 1990 population census. We control for cohort, regional, and year dummies in all the regressions. We also control for the log of the cohort population in case of inaccuracy in death incidence due to small cohort size. The results for the sex ratios are similar. Robust standard errors clustered at the county level are in parentheses. *,**, and $* * *$ stand for significance level at $10 \%, 5 \%$ and $1 \%$, respectively. 
Table 8-Sex Ratio and Working outside the Hometown: CFPS Rural Sample of One Child

Dependent variable: whether any family member worked outside the hometown last year

\begin{tabular}{|c|c|c|c|c|c|c|}
\hline \multirow{3}{*}{ Mean } & \multicolumn{3}{|c|}{ Household head aged 25 to 39} & \multicolumn{3}{|c|}{ Mother aged 25 to 39} \\
\hline & Son & Daughter & Whole & Son & Daughter & Whole \\
\hline & 0.23 & 0.18 & 0.22 & 0.25 & 0.17 & 0.23 \\
\hline \multirow[t]{2}{*}{ Std } & 0.42 & 0.39 & 0.41 & 0.43 & 0.37 & 0.42 \\
\hline & (1) & (2) & (3) & (4) & (5) & (6) \\
\hline Have a son $\times$ Sex ratio of & & & $0.008 * *$ & & & $0.006^{*}$ \\
\hline 10-19 age cohort & & & $(0.003)$ & & & $(0.003)$ \\
\hline \multirow[t]{2}{*}{ Have a son (dummy) } & & & $-0.902 * *$ & & & -0.651 \\
\hline & & & $(0.392)$ & & & $(0.398)$ \\
\hline \multirow[t]{2}{*}{ Sex ratio of age $10-19$ cohort } & $0.006 * *$ & -0.003 & -0.003 & $0.005 * *$ & -0.002 & -0.002 \\
\hline & $(0.002)$ & $(0.003)$ & $(0.002)$ & $(0.002)$ & $(0.003)$ & $(0.003)$ \\
\hline \multirow[t]{2}{*}{ Per capita income (log) } & -0.031 & -0.017 & -0.028 & -0.020 & $-0.056^{* *}$ & $-0.033^{*}$ \\
\hline & $(0.026)$ & $(0.038)$ & $(0.022)$ & $(0.024)$ & $(0.025)$ & $(0.019)$ \\
\hline \multirow[t]{2}{*}{ Family size } & $0.065^{* * *}$ & $0.068 * *$ & $0.067 * * *$ & $0.051 * *$ & 0.041 & $0.049 * * *$ \\
\hline & $(0.024)$ & $(0.032)$ & $(0.018)$ & $(0.025)$ & $(0.032)$ & $(0.019)$ \\
\hline \multirow[t]{2}{*}{ Household head's age } & 0.005 & -0.015 & -0.002 & 0.001 & -0.011 & -0.003 \\
\hline & $(0.009)$ & $(0.009)$ & $(0.006)$ & $(0.005)$ & $(0.007)$ & $(0.004)$ \\
\hline \multirow{2}{*}{$\begin{array}{l}\text { Household head's years of } \\
\text { schooling }\end{array}$} & 0.015 & $0.048 * *$ & $0.024 *$ & 0.009 & $0.040 * *$ & $0.019 *$ \\
\hline & $(0.015)$ & $(0.021)$ & $(0.013)$ & $(0.012)$ & $(0.019)$ & $(0.011)$ \\
\hline \multirow[t]{2}{*}{ Square of above variable } & $-0.002 * *$ & $-0.004 * * *$ & $-0.003 * * *$ & $-0.002 *$ & $-0.004 * * *$ & $-0.002 * * *$ \\
\hline & $(0.001)$ & $(0.001)$ & $(0.001)$ & $(0.001)$ & $(0.001)$ & $(0.001)$ \\
\hline \multirow[t]{2}{*}{ Male family head (dummy) } & $-0.111^{*}$ & -0.007 & $-0.078^{*}$ & $-0.177 * * *$ & -0.037 & $-0.128 * *$ \\
\hline & $(0.057)$ & $(0.082)$ & $(0.046)$ & $(0.063)$ & $(0.099)$ & $(0.055)$ \\
\hline \multirow[t]{2}{*}{ Han family head (dummy) } & $0.124 *$ & $0.206^{* * *}$ & $0.147 * * *$ & $0.176^{* * *}$ & $0.215 * * *$ & $0.183^{* * *}$ \\
\hline & $(0.068)$ & $(0.050)$ & $(0.046)$ & $(0.063)$ & $(0.050)$ & $(0.042)$ \\
\hline \multirow[t]{2}{*}{ Poor health (dummy) } & 0.050 & 0.245 & 0.089 & 0.067 & 0.081 & 0.063 \\
\hline & $(0.090)$ & $(0.193)$ & $(0.072)$ & $(0.084)$ & $(0.124)$ & $(0.063)$ \\
\hline \multirow[t]{2}{*}{ Have a child age 10-14 (dummy) } & -0.065 & 0.010 & -0.038 & -0.033 & 0.061 & -0.001 \\
\hline & $(0.060)$ & $(0.064)$ & $(0.043)$ & $(0.052)$ & $(0.054)$ & $(0.040)$ \\
\hline \multirow[t]{2}{*}{ Have a child age $15-19$ (dummy) } & 0.048 & $0.190 *$ & 0.095 & 0.024 & $0.235 * *$ & $0.094 *$ \\
\hline & $(0.073)$ & $(0.099)$ & $(0.058)$ & $(0.064)$ & $(0.090)$ & $(0.056)$ \\
\hline Observations & 223 & 89 & 312 & 254 & 97 & 351 \\
\hline
\end{tabular}

Source: China Family Panel Studies (2010).

Note: CFPS = China Family Panel Studies. The dependent variable equals 1 if any family member worked outside the hometown and 0 otherwise. We restrict the sample to families with one child age 5-19 and household heads ages 25-39. The columns with "Son" headings mean that the family only has a son while those with "Daughter" headings indicate that the family only has a daughter. Sex ratios for the age 10-19 cohort in 2010 are inferred from the male-to-female ratios (number of males per 100 females) among the age 0-9 cohort in 2000 based on China's 2000 population census. Robust standard errors clustered at the county level are in parentheses. $* * *, * *$, and * indicate significance at the $1 \%, 5 \%$, and $10 \%$ levels, respectively. 
Table 9-Sex Ratio, Working outside the Hometown, and Participation in Risky Jobs: CFPS Rural Sample of One Child

\begin{tabular}{|c|c|c|c|c|c|c|}
\hline & \multicolumn{3}{|c|}{$\underline{\log (1+\text { work months outside home })}$} & \multicolumn{3}{|c|}{ Risky jobs participation } \\
\hline & Son & Daughter & Whole & Son & Daughter & Whole \\
\hline & Mean 0.48 & Mean 0.41 & Mean 0.46 & Mean 0.24 & Mean 0.14 & Mean 0.21 \\
\hline & Std 0.92 & Std 0.92 & Std 0.92 & Std 0.43 & Std 0.35 & Std 0.41 \\
\hline & (1) & $(2$ & (3) & (4) & (5) & (6) \\
\hline Have a son $\times$ Sex ratio of & & & $0.017 * *$ & & & $0.006^{*}$ \\
\hline age $10-19$ cohort & & & $(0.008)$ & & & $(0.003)$ \\
\hline Have a son (dummy) & & & $-1.866^{* *}$ & & & -0.540 \\
\hline & & & $(0.920)$ & & & $(0.345)$ \\
\hline Sex ratio of age $10-19$ cohort & $0.012 * *$ & -0.006 & -0.006 & -0.000 & $-0.007 * * *$ & $-0.006 * * *$ \\
\hline & $(0.006)$ & $(0.006)$ & $(0.006)$ & $(0.002)$ & $(0.002)$ & $(0.002)$ \\
\hline Per capita income (log) & -0.059 & -0.026 & -0.050 & $0.137 * * *$ & $0.068 * *$ & $0.112 * * *$ \\
\hline & $(0.058)$ & $(0.078)$ & $(0.048)$ & $(0.031)$ & $(0.032)$ & $(0.026)$ \\
\hline Family size & $0.165 * * *$ & $0.182 * *$ & $0.170 * * *$ & -0.012 & $0.053 *$ & 0.006 \\
\hline & $(0.055)$ & $(0.088)$ & $(0.044)$ & $(0.024)$ & $(0.030)$ & $(0.020)$ \\
\hline Household head's age & 0.016 & -0.028 & 0.000 & 0.009 & 0.000 & 0.006 \\
\hline & $(0.018)$ & $(0.020)$ & $(0.013)$ & $(0.009)$ & $(0.012)$ & $(0.006)$ \\
\hline Household head's years of & $0.064 * *$ & $0.114 * * *$ & $0.076 * * *$ & 0.005 & 0.010 & 0.007 \\
\hline schooling & $(0.031)$ & $(0.042)$ & $(0.027)$ & $(0.016)$ & $(0.022)$ & $(0.012)$ \\
\hline Square of above variable & $-0.007 * * *$ & $-0.010 * * *$ & $-0.008 * * *$ & -0.000 & -0.001 & -0.001 \\
\hline & $(0.002)$ & $(0.003)$ & $(0.002)$ & $(0.001)$ & $(0.002)$ & $(0.001)$ \\
\hline Male family head (dummy) & $-0.288 * *$ & -0.076 & $-0.218 * *$ & -0.091 & -0.128 & $-0.093^{*}$ \\
\hline & $(0.128)$ & $(0.186)$ & $(0.103)$ & $(0.061)$ & $(0.086)$ & $(0.050)$ \\
\hline Han family head (dummy) & $0.283 * *$ & $0.417 * * *$ & $0.323^{* * *}$ & $0.143 * *$ & $0.145^{*}$ & $0.153 * * *$ \\
\hline & $(0.117)$ & $(0.121)$ & $(0.085)$ & $(0.058)$ & $(0.074)$ & $(0.045)$ \\
\hline Poor health (dummy) & 0.151 & 0.473 & 0.216 & 0.021 & $-0.151 * *$ & -0.013 \\
\hline & $(0.220)$ & $(0.371)$ & $(0.160)$ & $(0.090)$ & $(0.062)$ & $(0.074)$ \\
\hline Have a child age 10-14 (dummy) & -0.132 & 0.012 & -0.079 & $-0.146 * *$ & $0.152 *$ & -0.048 \\
\hline & $(0.118)$ & $(0.129)$ & $(0.086)$ & $(0.057)$ & $(0.078)$ & $(0.047)$ \\
\hline Have a child age $15-19$ (dummy) & 0.122 & 0.374 & 0.209 & -0.106 & 0.072 & -0.043 \\
\hline & $(0.151)$ & $(0.232)$ & $(0.128)$ & $(0.071)$ & $(0.101)$ & $(0.059)$ \\
\hline Observations & 223 & 89 & 312 & 223 & 89 & 312 \\
\hline
\end{tabular}

Source: China Family Panel Studies (2010).

Note: CFPS = China Family Panel Studies. We restrict the sample to families with one child age 5-19 and household heads ages 25-39. Dangerous jobs are jobs related to firefighting, public security, mineral mining, well drilling, oil and gas exploration, construction, electricity supply, installation and debugging of electrical equipment, and operation of mechanical equipment. The columns with "Son" headings mean that the family only has a son while those with "Daughter" headings indicate that the family only has a daughter. Sex ratios for the age 10-19 cohort in 2010 are inferred from the male-to-female ratios (number of males per 100 females) among the age 0-9 cohort in 2000 based on China's 2000 population census. Robust standard errors clustered at the county level are in parentheses. $* * *, * *$, and $*$ indicate significance at the $1 \%, 5 \%$, and $10 \%$ levels, respectively. 
Table 10-Sex Ratio and Work-Related Injury Insurance Coverage

\begin{tabular}{|c|c|c|c|c|c|c|}
\hline & \multicolumn{2}{|c|}{ OLS } & \multirow[b]{2}{*}{ (3) } & \multicolumn{2}{|c|}{ 2SLS } & \multirow[b]{2}{*}{$(6)$} \\
\hline & (1) & (2) & & (4) & $(5)$ & \\
\hline $\begin{array}{l}\text { Sex ratio of age } 10-19 \text { cohort } \\
\quad(\text { mean }=112.2, \operatorname{std}=8.6)\end{array}$ & $\begin{array}{c}-0.014 * * * \\
(0.003)\end{array}$ & $\begin{array}{c}-0.012 * * * \\
(0.003)\end{array}$ & $\begin{array}{c}-0.010 * * * \\
(0.003)\end{array}$ & $\begin{array}{c}-0.011 * * * \\
(0.004)\end{array}$ & $\begin{array}{c}-0.012 * * * \\
(0.005)\end{array}$ & $\begin{array}{c}-0.020 * * * \\
(0.009)\end{array}$ \\
\hline $\begin{array}{l}\text { Union members to total } \\
\text { staff (unionization) }\end{array}$ & & $\begin{array}{c}0.258 * * * \\
(0.072)\end{array}$ & $\begin{array}{l}0.216 * * * \\
(0.073)\end{array}$ & & $\begin{array}{l}0.310 * * * \\
(0.050)\end{array}$ & $\begin{array}{l}0.133 * * \\
(0.063)\end{array}$ \\
\hline $\begin{array}{l}\text { Female staff } \\
\text { to total staff ratio }\end{array}$ & & $\begin{array}{l}-0.048 \\
(0.132)\end{array}$ & $\begin{array}{l}-0.096 \\
(0.131)\end{array}$ & & $\begin{array}{l}-0.101 \\
(0.120)\end{array}$ & $\begin{array}{l}-0.123 \\
(0.122)\end{array}$ \\
\hline $\begin{array}{l}\text { Staff from rural area } \\
\text { to total staff ratio }\end{array}$ & & $\begin{array}{c}0.118 \\
(0.150)\end{array}$ & $\begin{array}{l}-0.071 \\
(0.133)\end{array}$ & & $\begin{array}{c}0.115 \\
(0.128)\end{array}$ & $\begin{array}{l}-0.061 \\
(0.132)\end{array}$ \\
\hline $\begin{array}{l}\text { Female union members } \\
\text { to total staff ratio }\end{array}$ & & $\begin{array}{c}0.044 \\
(0.133)\end{array}$ & $\begin{array}{c}0.043 \\
(0.130)\end{array}$ & & $\begin{array}{c}0.104 \\
(0.117)\end{array}$ & $\begin{array}{c}0.052 \\
(0.118)\end{array}$ \\
\hline $\begin{array}{l}\text { Union members from } \\
\text { rural area to total staff }\end{array}$ & & $\begin{array}{l}-0.032 \\
(0.138)\end{array}$ & $\begin{array}{c}0.127 \\
(0.122)\end{array}$ & & $\begin{array}{l}-0.021 \\
(0.126)\end{array}$ & $\begin{array}{c}0.127 \\
(0.129)\end{array}$ \\
\hline $\begin{array}{l}\text { Ratio of grassroots staff } \\
\text { on board of directors }\end{array}$ & & $\begin{array}{c}0.080 \\
(0.070)\end{array}$ & $\begin{array}{r}0.072 \\
(0.069)\end{array}$ & & $\begin{array}{c}0.058 \\
(0.061)\end{array}$ & $\begin{array}{r}0.103 \\
(0.063)\end{array}$ \\
\hline $\begin{array}{l}\text { Ratio of grassroots staff } \\
\text { on board of supervisors }\end{array}$ & & $\begin{array}{c}0.305 * * * \\
(0.048)\end{array}$ & $\begin{array}{c}0.270 * * * \\
(0.049)\end{array}$ & & $\begin{array}{c}0.341 * * * \\
(0.044)\end{array}$ & $\begin{array}{c}0.202 * * * \\
(0.054)\end{array}$ \\
\hline Log sales & & $\begin{array}{c}0.036 * * * \\
(0.008)\end{array}$ & $\begin{array}{c}0.031 * * * \\
(0.009)\end{array}$ & & $\begin{array}{c}0.039 * * * \\
(0.006)\end{array}$ & $\begin{array}{c}0.027 * * * \\
(0.006)\end{array}$ \\
\hline $\begin{array}{l}\text { Operating profits } \\
\text { to sales ratio }\end{array}$ & & $\begin{array}{c}0.093 \\
(0.075)\end{array}$ & $\begin{array}{c}0.110 \\
(0.071)\end{array}$ & & $\begin{array}{c}0.080 \\
(0.064)\end{array}$ & $\begin{array}{l}0.115^{*} \\
(0.065)\end{array}$ \\
\hline Three expenses & & $0.521 * * *$ & $0.455^{* * *}$ & & $0.519 * * *$ & $0.459 * * *$ \\
\hline to sales ratio & & $(0.120)$ & $(0.113)$ & & $(0.087)$ & $(0.089)$ \\
\hline $\begin{array}{l}\text { Short-term debt } \\
\text { to sales ratio }\end{array}$ & & $\begin{array}{l}0.019 * \\
(0.011)\end{array}$ & $\begin{array}{c}0.012 \\
(0.009)\end{array}$ & & $\begin{array}{l}0.020 * * \\
(0.008)\end{array}$ & $\begin{array}{c}0.013 \\
(0.008)\end{array}$ \\
\hline $\begin{array}{l}\text { Fixed assets } \\
\text { to sales ratio }\end{array}$ & & $\begin{array}{c}-0.036 * * \\
(0.016)\end{array}$ & $\begin{array}{l}-0.022 \\
(0.016)\end{array}$ & & $\begin{array}{c}-0.038 * * * \\
(0.014)\end{array}$ & $\begin{array}{l}-0.023 \\
(0.015)\end{array}$ \\
\hline Industry \& owner type & No & No & Yes & No & No & Yes \\
\hline Province dummies & No & No & Yes & No & No & Yes \\
\hline F of the first stage & & & & $53.71 * * *$ & $39.16^{* * *}$ & $10.82 * * *$ \\
\hline Hausman-Wu statistic & & & & 0.55 & $5.92 * *$ & $4.52 * *$ \\
\hline Hansen $\mathbf{J}$ statistic & & & & 6.29 & 6.93 & 6.18 \\
\hline Observations & 3,329 & 3,329 & 3,329 & 3,329 & 3,329 & 3,329 \\
\hline
\end{tabular}

Source: All-China Federation of Trade Unions survey (2009).

Note: OLS = ordinary least squares; 2SLS = two-stage least squares. F of the first stage indicates the Kleibergen-Paap Wald F statistics in the first-stage regressions. The instrumental variables for the sex ratio are the amount of the one-child bonus (B), premium for higher-order birth (P), log of population density (L), and $\mathrm{B} \times \mathrm{L}, \mathrm{P} \times \mathrm{L}$. Sex ratios of the age 10-19 cohort are inferred from the age 0-9 cohort in the population census in 2000. Robust standard errors clustered at the county level are in parentheses. The symbols $* * *, * *$, and $*$ indicate statistical significance at the $1 \%, 5 \%$, and $10 \%$ levels, respectively. 
Figure 1-Sex Ratio and Work Injury Disability Rate across Provinces

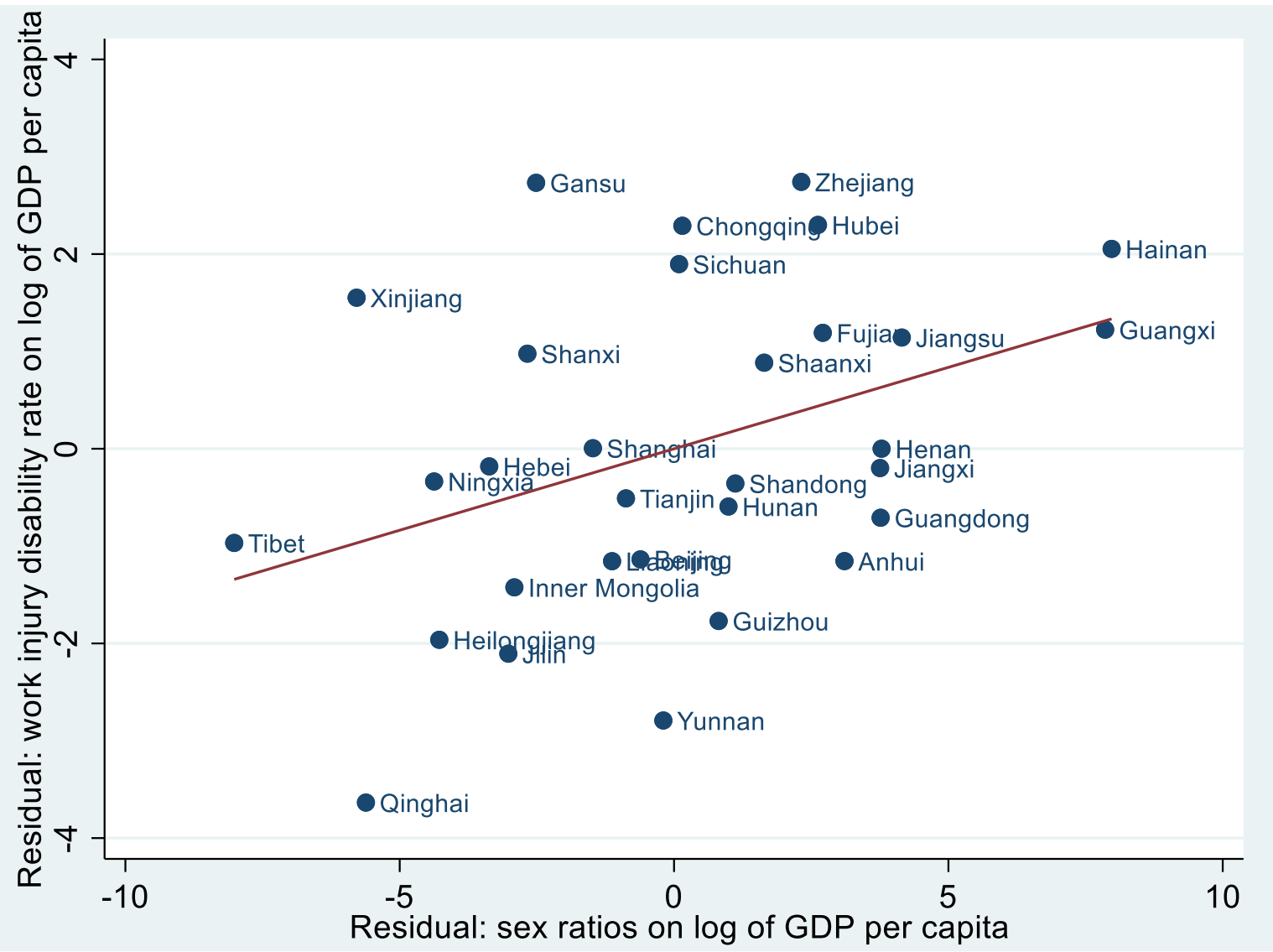

Sources: China National Sample Survey on Disability (2006); 1\% sample of China population census in 2000.

Note: We use the Frisch-Waugh theorem to exclude the impacts of the log of gross domestic product (GDP) per capita. The horizontal axis is the residual of the regression of sex ratios on log of GDP per capita, and the vertical axis is the residual of the regression of the work injury disability rate on log of GDP per capita. Work injury disability rate is the number of disabled people due to work injury divided by the average number of workers in a certain period (unit: 1/100,000). Sex ratios of the age 10-19 premarital cohort in 2006 are calculated as the male-to-female ratios for the age 4-13 cohort in the 2000 population census. For the fitted line, the $t$ value for the slope is 2.50 . 


\section{Figure 2-Sex Ratio and Work-Related Death Rate at the National Level}

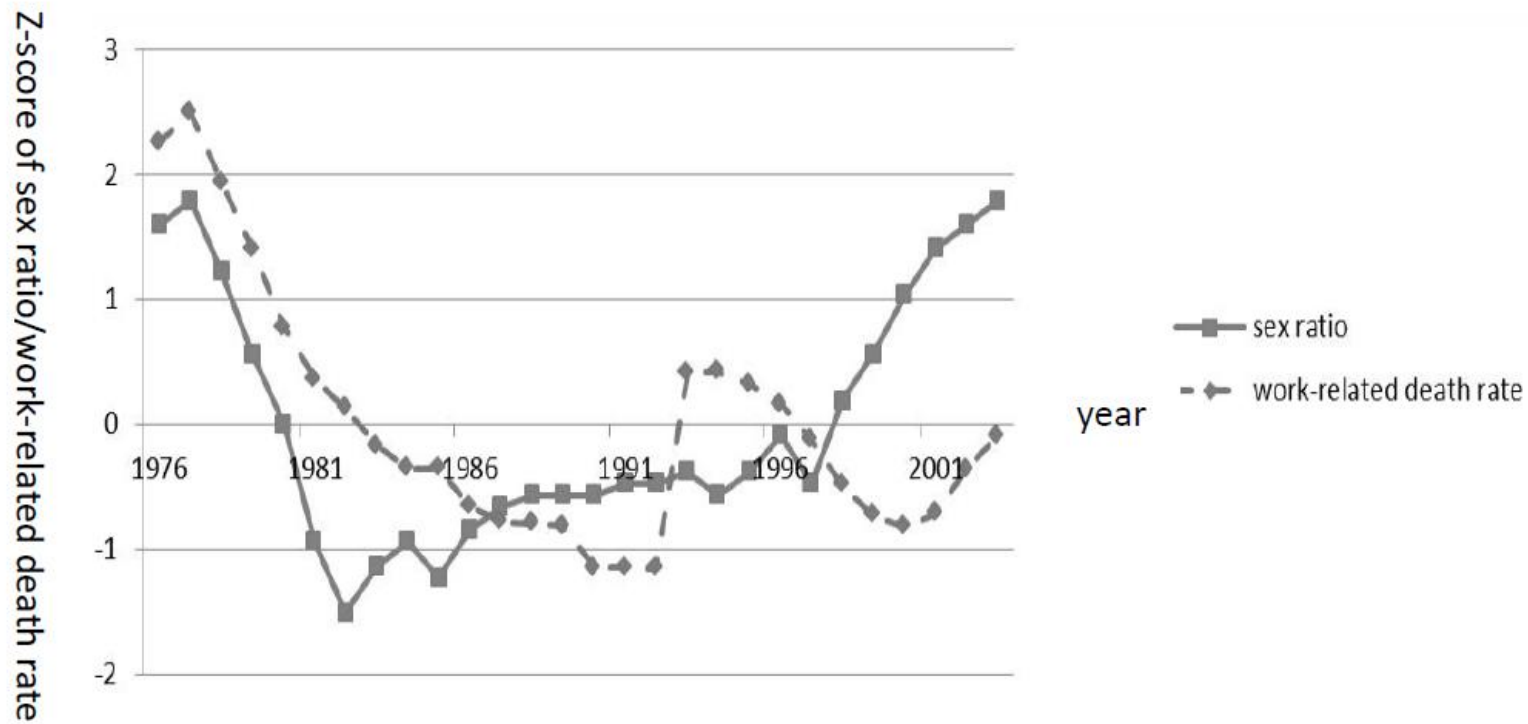

Sources: China's Work Safety Yearbook (2000-2004); China Statistical Yearbook (1978-2004).

Note: The sex ratio is defined as the male-to-female ratio at birth 20 years earlier. Sex ratios at birth in 1982, 1990, and 2000 at the national level are published figures from China's population censuses. Since the disaggregate sex ratios at birth in 1980 and 1990 are not publicly available, we use sex ratios for the age 20 cohort and age 10 cohort, respectively, from the 2000 census to approximate them. Work-related death rate is defined as the number of deaths caused by work-related accidents divided by the average number of workers in a certain period (unit: 1/100,000). Both variables have been rescaled by subtracting the mean and dividing by the standard deviation. 
Figure 3-Sex Ratio and Work-Related Deaths across Provinces

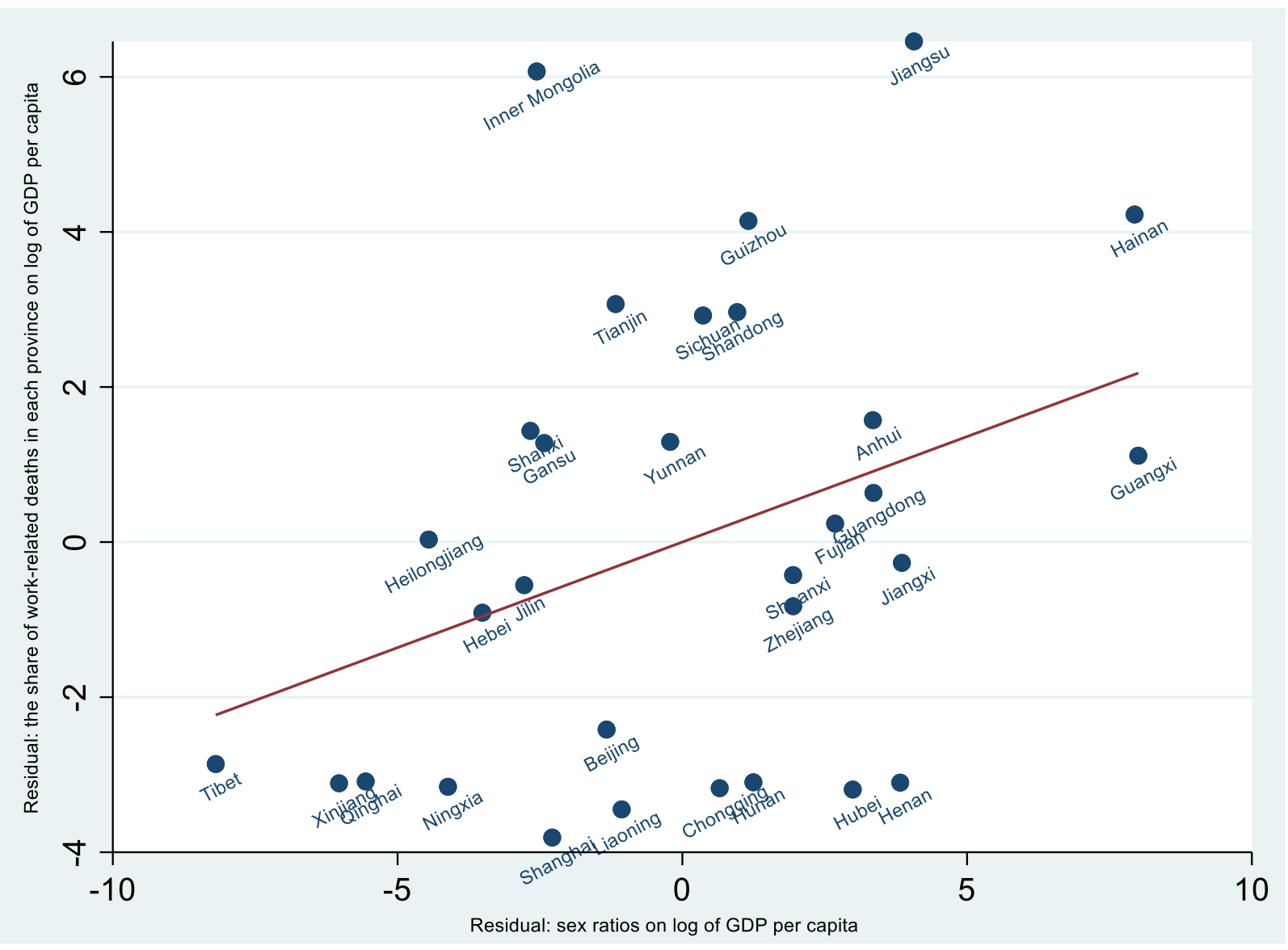

Source: Website of the State Administration of Work Safety (http://media.chinasafety.gov.cn:8090/iSystem/shigumain.jsp).

Note: We use the Frisch-Waugh theorem to exclude the impacts of the log of gross domestic product (GDP) per capita. The horizontal axis is the residual of the regression of sex ratios on log of GDP per capita, and the vertical axis is the residual of the regression of the share of work-related deaths in each province to the nationwide total work-related deaths on log of GDP per capita. Sex ratios of the age 10-19 premarital cohort in 2009 are calculated as the male-to-female ratios for the age 0-9 cohort in the 2000 population census. For the fitted line, the $t$ value for the slope is 1.92 . 
Figure 4-Family Planning Policy in 1980 and Accidental Death Rates in 1991 across Provinces

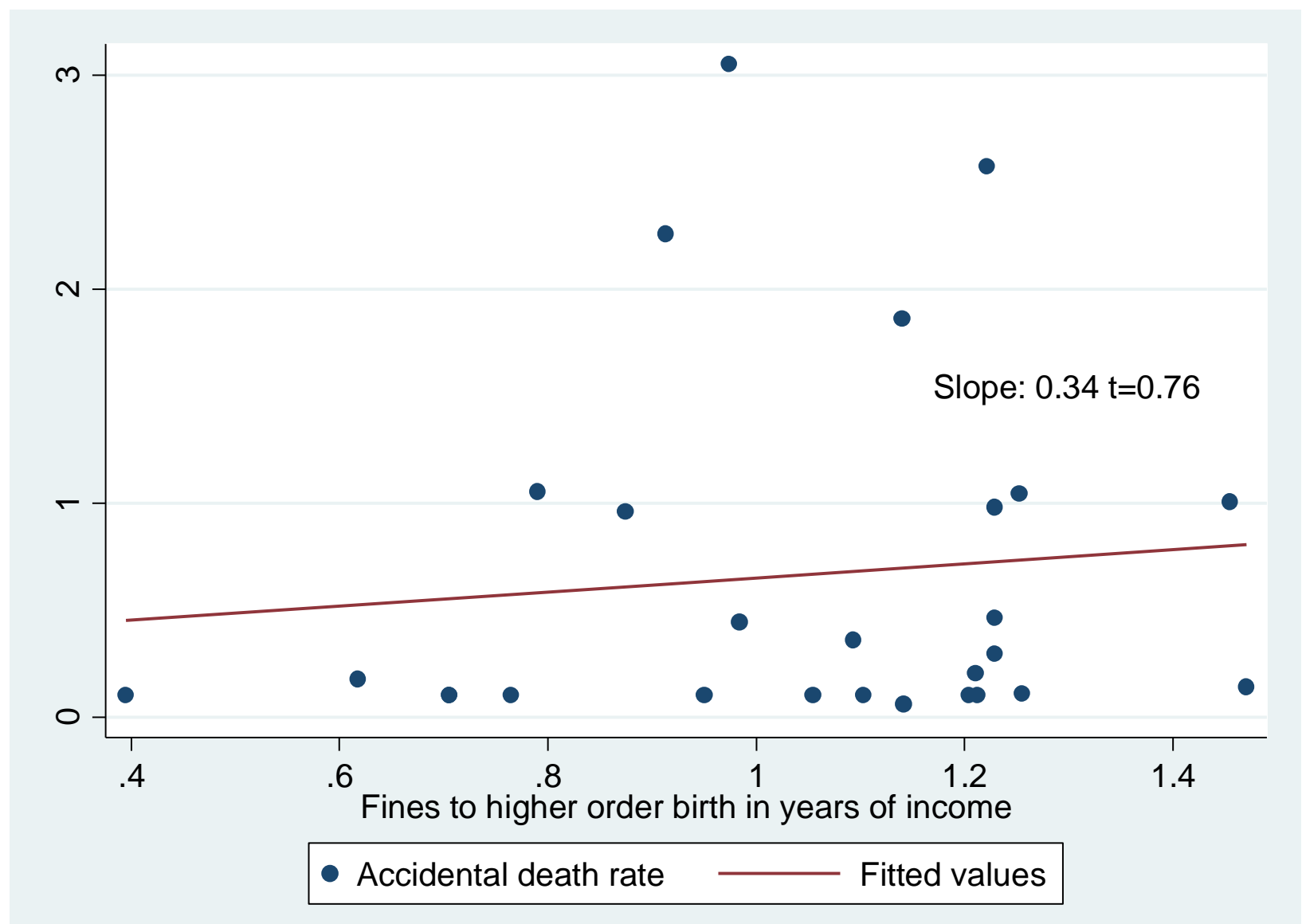

Note: The vertical axis is the death rate due to accidental falls and fires and flames in 1991 for the age 25-39 cohort. The death rate is defined as the number of deaths due to a certain cause per 100,000 people based on the National Disease Surveillance Points System data set. The horizontal axis is the fines for higher order births in years of income in 1980. 


\section{Online Appendix A: Major Outcome Variables and Data Sources}

\section{Work-Related Disability}

The individual-level disability data used in this paper come from the Second China National Sample Survey on Disability (shortened as the National Disability Survey), conducted jointly in 2006 by the National Bureau of Statistics, the Ministry of Civil Affairs, and the China Disabled Persons' Federation and headed by the leading group of the National Disability Survey. ${ }^{30}$ The survey uses stratified, multi-phase, and cluster probability sampling and is nationally representative. The survey designers first assigned a number of counties/districts to be surveyed in each province. Counties (or districts in cities) were then randomly selected for each province. In total, 734 counties (or districts) were chosen. For each county (or district), an average of 4 towns was further sampled. In each town, a random sample of 840 households on average was selected. In total, 2,980 towns (townships in rural areas or communities in cities) were sampled. Across the nation, 771,797 households and 2,526,145 individuals were included in the sample. In the first stage, enumerators visited each household and interviewed all household members who were age seven years or older and screened for disabled people using relatively generous criteria to minimize the error of missing disabled persons. In Step 2, if a household member was regarded as possibly disabled, the enumerators would further fill in a detailed form for the household member. For children under age six, the enumerators would complete a health examination record. In Step 3, experienced doctors examined and assessed possibly disabled people at designated stations. If a person was confirmed as being disabled, an informational form on disability would be filled.

The survey includes individuals' basic information and their economic, social, and disability status. Basic information refers to an individual's age, gender, family size, and address. Economic and social status is reflected by school attainment, personal income, and marital status. For those identified as disabled, disability information is more detailed, consisting of disability status, pathogenic causes, and degree of severity. Disability is classified into five categories: visual, hearing and speech, cognitive, mental, and physical. The key variable of interest for this research is physical disability caused by work-related injuries.

\footnotetext{
${ }^{30}$ For details on the survey, see Documentation of the Second China National Sample Survey on Disability (Office of the Second China National Sample Survey on Disability, 2007).
} 


\section{Mortality}

The data on deaths come from China's National Disease Surveillance Points System (NDSPS), which includes all deaths (with exhaustive information on causes of death) in 145 sites - chosen to be nationally representative during 1991-2000, so that it captures China's variation in wealth and geographic dispersion. Several studies have used this data set and provided a detailed description of the data (Ebenstein, 2012; Chen et al., 2013).

Because an urban sample may include migrants, and our story of working outside the hometown and taking risks to accumulate wealth is more relevant for rural people, we focus on the rural sites in the NDSPS data. ${ }^{31}$ The measurement error of a location's mortality owing to migration is not a big challenge to our results in the rural sample of the NDSPS data for several reasons. First, the system assigns deaths according to an individual's hukou (household registration system in Chinese) or place of birth. If the death occurs away from the hometown, the family is instructed to report the death wherever it happens and a site official is expected to accurately record the death at the site of the deceased's original registration. Second, the hukou system requires that the death certificate reports the hukou or place of birth, and that information is checked by a local official who provides an official stamp of verification on the death certificate. Third, according to Meng (2012), massive migration did not occur until the end of the 1990s and the direction of migration is from inland to coastal areas and from rural to urban areas. ${ }^{32}$ To address the concern of outmigration, we also restrict our sample to the early period of the 1990s and exclude the largest destination provinces of migration as robustness checks.

\section{Working outside the Hometown and Risky Jobs}

The data on working outside the hometown (probability and time) and participation in risky jobs are from the China Family Panel Studies (CFPS) 2010, a large-scale survey of 14,798 families and 33,600 adults in 25 Chinese provinces in 2010. It was funded by a "National 985 Program"

\footnotetext{
31 The list of the sites is in Appendix E.

32 In 1997, the government introduced a new policy ("hold on to the large, let go of the small"), which aimed at maintaining the largest 1,000 state-owned enterprises and pushing smaller ones into the market to compete with non-state firms, while allowing the remaining loss-making state firms to go bankrupt. Since then, the private sector has expanded quickly and employs a great number of migrant workers.
} 
at Peking University — a special government research grant to the university — and carried out by the Institute of Social Science Survey of Peking University. It contains specific information not only about family structure and the demographics of individuals, but also about types of jobs and working outside the hometown. Since working outside the hometown and taking risky jobs are more common for rural people, we focus on the rural sample of the CFPS 2010.

\section{Employers' Investment in Workplace Safety}

Purchasing work-related injury insurance is an important aspect of employers' investment in workplace safety. The Regulations on Work-Related Injury Insurance in China, implemented in 2004, stipulate that all enterprises in China must pay for the premium of work-related injury insurance (Article 2) for their employees. However, in practice, many firms do not purchase such insurance for all employees. Using a survey implemented by the All-China Federation of Trade Unions in 2009, which covers firms in Beijing, Shanghai, and Tianjin, as well as the provinces of Liaoning, Jiangsu, Zhejiang, Guangdong, Hebei, Henan, Hubei, Sichuan, and Shaanxi, and includes detailed information about work-related injury insurance coverage and the situation of unions, we investigate the impacts of imbalanced sex ratios on employers' provision of work-related injury insurance. The survey asks firms about the number of workers covered by work-related injury insurance; the share of union members, female union members, rural union members, female employees, and rural employees in total employees; and the share of grassroots employees on the board of directors and supervisors. Firm-level financial indicators, such as sales, operating profits, fixed assets, short-term debt, and the three expenses (i.e., operating expense, administrative expense, and financial expense), are obtained from the Annual Survey of Industrial Firms data set compiled by the National Bureau of Statistics. ${ }^{33}$

\footnotetext{
33 The survey by the All-China Federation of Trade Unions does not include detailed firm operational information. We match the firms in the survey with the Annual Survey of Industrial Firms data set to obtain such additional information.
} 


\section{Online Appendix B: Appendix Figures}

\section{Figure B1-Ratio of Male to Female Workers and Injury Rate at the Industry Level}

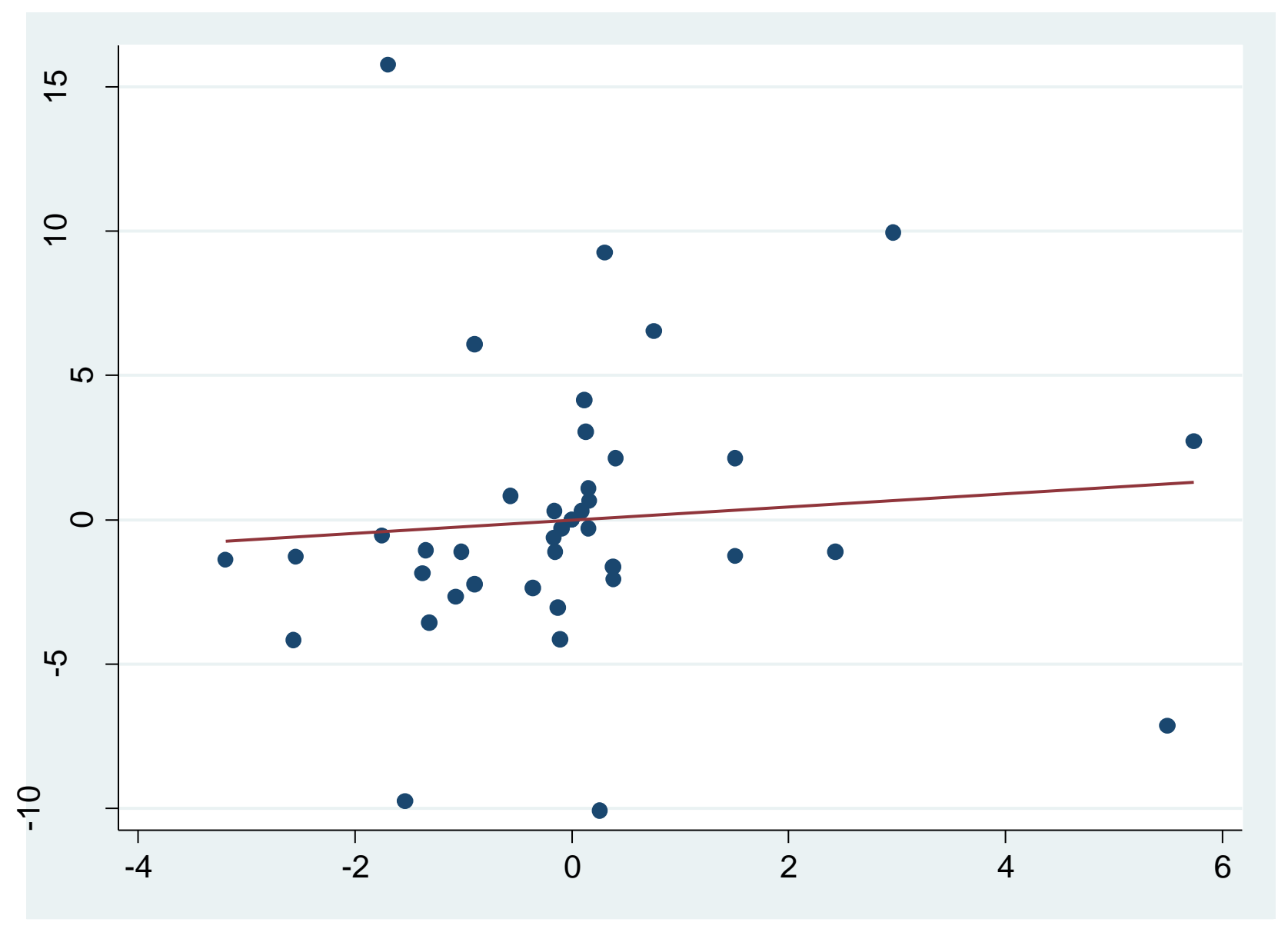

Source: Bureau of Labor Statistics (2000).

Note: To exclude the intrinsic characteristics of each sector, we add the sector dummies. We use the Frisch-Waugh theorem to exclude the impacts of the sector dummies. The horizontal axis is the residual of the regression of the ratio of male to female workers in each industry on sector dummies, and the vertical axis is the residual of the regression of the fatal injury rate in each industry on sector dummies. The industry classification is SIC 2 digits (mining, construction, manufacturing sectors). The ratio of male to female workers at the industry level is from the current population survey of the Bureau of Labor Statistics (BLS) of the United States in 2000. The injury rate is the number of injuries per 100 full-time workers and is calculated as: (number of injuries and illnesses/total hours worked by all employees during the calendar year) $\times 200,000$, where 200,000 is the base for 100 equivalent full-time workers (working 40 hours per week, 50 weeks per year). The data are from the injuries, illnesses, and fatalities program of the US BLS in 2000. Three industries with an extremely high male-to-female labor ratio (coal mining, construction, and nonmetallic mineral product manufacturing) are excluded. For the fitted line, the $t$ value for the slope is 0.43 . If including the three outliers, the t-value for the slope is 0.01 . 
Figure B2-Sex Ratio and Labor Safety Protection

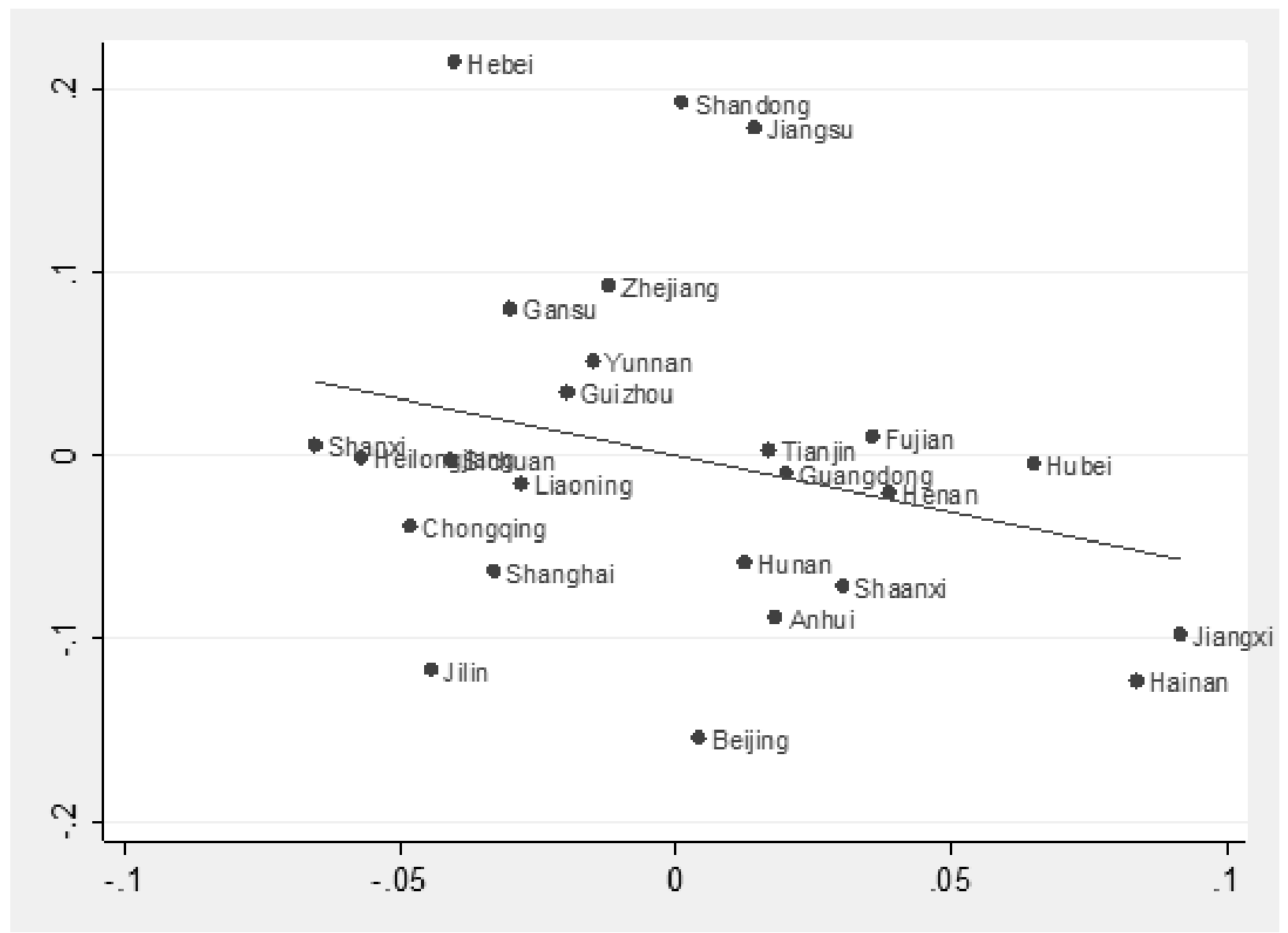

Source: Chinese Trade Unions Statistics Yearbook (2012).

Note: We use the Frisch-Waugh theorem to exclude the impacts of the log of gross domestic product (GDP) per capita. The horizontal axis is the residual of the regression of sex ratios on log of GDP per capita, and the vertical axis is the residual of the regression of the ratio of trade unions that have set up labor protection, supervision, and inspection committees on log of GDP per capita. Sex ratios are calculated as male-to-female ratios for the age 10-19 cohort in the 2010 population census. The $t$ value for the fitted line is -1.76 . 


\section{Figure B3 - Sex Ratio and Labor Dispute Mediation: Placebo Test}

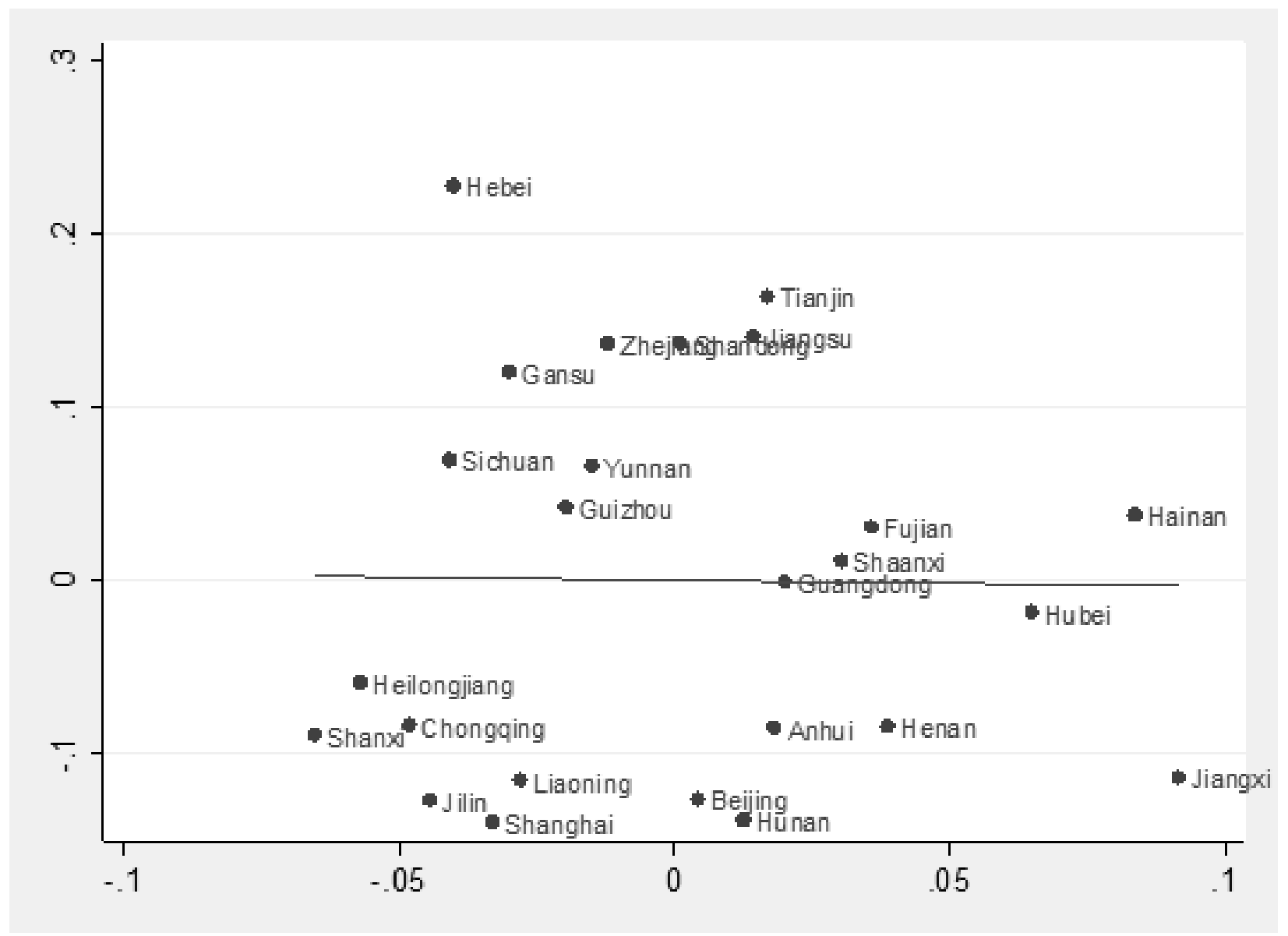

Source: Chinese Trade Unions Statistics Yearbook (2012).

Note: We use the Frisch-Waugh theorem to exclude the impacts of the log of gross domestic product (GDP) per capita. The horizontal axis is the residual of the regression of sex ratios on log of GDP per capita, and the vertical axis is the residual of the regression of the share of trade unions that have set up labor dispute mediation committees on log of GDP per capita. Sex ratios are calculated as the male-to-female ratios for the age 10-19 cohort in the 2010 population census. The $t$ value for the fitted line is -0.07 . 


\section{Online Appendix C: Appendix Tables}

\section{Table C1—Characteristics of Household Heads by First-Born Gender and Local Sex Ratios}

\begin{tabular}{|c|c|c|c|}
\hline \multicolumn{4}{|c|}{ Panel A: Household head's average years of education } \\
\hline & With Son & With Daughter & Difference \\
\hline & (1) & $(2)$ & $(3)=(1)-(2)$ \\
\hline High sex ratio regions (a) & 5.83 & 5.36 & $0.47(\mathrm{t}=1.45)$ \\
\hline Low sex ratio regions (b) & 5.53 & 5.71 & $-0.18(\mathrm{t}=-0.57)$ \\
\hline Difference $(c)=(a)-(b)$ & $0.30(\mathrm{t}=0.96)$ & $-0.35(\mathrm{t}=-1.07)$ & $0.65(\mathrm{t}=1.44)$ \\
\hline \multicolumn{4}{|c|}{ Panel B: Household head's average age } \\
\hline & Son & Daughter & Difference \\
\hline & (1) & (2) & $(3)=(1)-(2)$ \\
\hline High sex ratio regions (a) & 34.92 & 35.03 & $-0.11(\mathrm{t}=-0.32)$ \\
\hline Low sex ratio regions $(b)$ & 34.62 & 34.55 & $0.07(\mathrm{t}=0.16)$ \\
\hline Difference $(c)=(a)-(b)$ & $0.30(\mathrm{t}=1.25)$ & $0.48(\mathrm{t}=1.54)$ & $-0.18(\mathrm{t}=-0.34)$ \\
\hline
\end{tabular}

Source: China Family Panel Studies (2010).

Note: The table reports the mean of household head's years of education and age in different regions. We restrict the sample to families with one child age 5-19 and household heads ages 25-39. The columns with "Son" headings mean that the family's firstborn is a son, while those with "Daughter" headings indicate that the family's firstborn is a daughter. We use the median of the sex ratio variable in the whole sample to divide the full sample into high sex ratio regions (higher than the median) and low sex ratio regions (lower than the median). The sex ratio variable is inferred from the male-to-female ratios (number of males per 100 females) among the age 0-9 cohort in 2000 based on China's 2000 population census. 
Table C2 - Sex Ratio and Strictness of the One-Child Policy

\begin{tabular}{lccccc}
\hline & \multicolumn{2}{c}{ Sex ratio of children's cohort } & & \multicolumn{2}{c}{ Sex ratio of 10 years older cohort } \\
\cline { 2 - 3 } & $(1)$ & $(2)$ & $(3)$ & & $(4)$ \\
Fines for higher order birth & $2.66^{* * *}$ & & $2.62^{* * *}$ & -0.83 \\
in multiples of yearly income & $(0.92)$ & & $(0.85)$ & $(0.57)$ \\
Log of one-child bonus & & & & 1.57 \\
Observations & & $-6.19^{* * *}$ & $-6.10^{* *}$ & $(2.93)$ \\
\hline
\end{tabular}

Sources: The family planning policy variables come from Ebenstein (2010). The sex ratio variables are from China Population Census in 1990 and 2000.

Note: Robust standard errors are in parentheses. $* * *, * *$, and * indicate significance level at $1 \%, 5 \%$ and $10 \%$, respectively. 
Table C3 - Top 50 Causes of Death and the Sex Ratio

\begin{tabular}{|c|c|c|c|}
\hline & Cause of death & Regression coefficient for sex ratio & Percentage of deaths in total deaths \\
\hline 1 & Cerebrovascular disease & 0.410 & 17.37 \\
\hline 3 & Malignant neoplasm of digestive organs and peritoneum & 1.119 & 10.34 \\
\hline 5 & Ischemic heart disease & $0.955^{*}$ & 5.48 \\
\hline 6 & Signs, symptoms, and ill-defined conditions & 0.883 & 3.79 \\
\hline 7 & Disease of other parts of the digestive system & 0.937 & 3.59 \\
\hline 10 & Transport accidents & 0.035 & 2.65 \\
\hline 11 & Suicide and self-inflicted injury & 0.557 & 2.24 \\
\hline 12 & Other accidents, including late effects & 0.280 & 2.23 \\
\hline 13 & Diseases of urinary system & 0.148 & 1.88 \\
\hline 14 & Tuberculosis & 0.451 & 1.45 \\
\hline 18 & Certain conditions originating in the perinatal period & 0.261 & 1.11 \\
\hline 19 & Malignant neoplasm of genitourinary organs & 0.367 & 1.02 \\
\hline 20 & Accidents due to fires and flames or accidental falls & $1.383^{*}$ & 0.85 \\
\hline 21 & Malignant neoplasm of lymphatic and haemopoietic tissue & 0.461 & 0.85 \\
\hline 22 & Mental disorders & 0.052 & 0.76 \\
\hline 23 & Malignant neoplasm of bone, connective tissue, skin, and breast & $0.296^{*}$ & 0.76 \\
\hline 24 & Disease of the nervous system & 0.216 & 0.66 \\
\hline 25 & Other violence & 0.495 & 0.65 \\
\hline 26 & Accidental poisoning & 0.189 & 0.62 \\
\hline 27 & Malignant neoplasm of other and unspecified sites & 0.130 & 0.59 \\
\hline 28 & Intestinal infectious diseases & 0.263 & 0.51 \\
\hline 36 & Intracranial and internal injuries & 2.520 & 0.33 \\
\hline 37 & Diseases of the musculoskeletal systems and connective tissue & -0.078 & 0.3 \\
\hline 38 & Fractures & 1.757 & 0.23 \\
\hline 39 & Diseases of blood and blood-forming organs & 0.160 & 0.22 \\
\hline 40 & Nutritional deficiencies & 0.1110 & 0.21 \\
\hline 41 & Burns & 0.398 & 0.20 \\
\hline 42 & Complications of medical and surgical conditions & 0.222 & 0.20 \\
\hline 43 & Benign neoplasm & 0.011 & 0.18 \\
\hline 44 & Direct obstetric causes & 0.785 & 0.13 \\
\hline 45 & Disorders of the eye and adnexa & 0.029 & 0.13 \\
\hline 46 & Other injuries, early complications of trauma & 0.876 & 0.11 \\
\hline 47 & Other and late effects of infectious and parasitic diseases & 0.176 & 0.10 \\
\hline 48 & Diseases of skin and subcutaneous tissue & -0.047 & 0.08 \\
\hline 49 & Other and unspecified neoplasm & 0.021 & 0.08 \\
\hline 50 & Open wound and injury to blood vessels & $2.052 *$ & 0.07 \\
\hline
\end{tabular}


Note: the regression coefficient before sex ratio is based on the two-stage least squares estimates. The regression specifications and other control variables are the same as those in Table $4 . *$ indicates that the coefficient is significant at the $1 \%$ or $5 \%$ level (same or higher significance level than accidental deaths).

Table C4- Sex Ratio and Accidental Death: County-Cohort-Year Regressions Using the Sex Ratio of the Age 10-19 Cohort

Dependent variable: Accidental death rate

OLS

(1)

$0.709 * *$

(0.296)
2SLS

(2)

$1.277 * *$

(0.619)

$73.14 * * *$

$4.80 * *$

0.17

1,980

\section{Observations}

1,980

Source: National Disease Surveillance Points System (1991-2000).

Note: OLS = ordinary least squares; 2SLS = two-stage least squares. Parents' cohort is ages 25-39. F of the first stage indicates the Kleibergen-Paap Wald F statistic in the first stage regressions. Instrumental variables (IVs) for the sex ratio are fines for higher order births in years of income (F), log of the amount of the one-child bonus (B), log of population density (L), and F $\times \mathrm{L}$, $\mathrm{B} \times \mathrm{L}$. If we use $\mathrm{F}$ or $\mathrm{B}$ alone as the IV for the sex ratio, or $\mathrm{F}, \mathrm{B}, \mathrm{F} \times \mathrm{L}, \mathrm{B} \times \mathrm{L}$ as IVs for the sex ratio, the results are qualitatively similar. The dependent variable is death incidence of accidents caused by fire and flames or accidental falls. The sex ratio variable is inferred from the $1 \%$ sample of the 1990 census. That is, in 1991 (1992), the sex ratio of the age 10-19 cohort is calculated from the age 9-18 (8-17) cohort of the 1990 census, and so forth. We use the age 10-19 cohort because in 2000, people who were ages 5-9 were not born yet in 1990. We control for cohort, regional, and year dummies in all the regressions. We also control for the log of the cohort population in case of inaccuracy in death incidence due to small cohort size. The results for the sex ratios are similar. Robust standard errors clustered at the county level are in parentheses. *,**, and *** stand for significance level at $10 \%, 5 \%$ and $1 \%$, respectively. 


\section{Online Appendix D: List of Sites in the National Disease Surveillance Data Set}

Tianchang Xian, Tong Xian, Hui'an Xian, Jianyang Xian, Yongding Xian, Jingtai Xian, Lintan Xian, Nanxiong Xian, Taishan Xian, Wuhua Xian, Binyang Xian, Hepu Xian, Lingyun Xian, Luocheng Mulaozu Zizhixian, Dushan Xian, Meitan Xian, Shibing Xian, Yuping Dongzu Zizhixian, Fengning Manzu Zizhixian, Huanghua Shi, Wu'an Shi, Baoqing Xian, Yi'an Xian, Fugou Xian, Sui Xian, Tanghe Xian, Gucheng Xian, Xiangyang Xian, Fenghuang Xian, Liuyang Xian, Yueyang Xian, Sunite-You Qi, Haimen Xian, Luhe Xian, Longnan Xian, Wuning Xian, Dehui Xian, Longjing Shi, Dengta Xian, Fengcheng Manzu Zizhixian, Helan Xian, Yanchi Xian, Zhongwei Xian, Huzhu Tuzu Zizhixian, Menyuan Huizu Zizhixian, Luochuan Xian, Mei Xian, Junan Xian, Liangshan Xian, Mouping Xian, Penglai Xian, Yiyuan Xian, Yucheng Xian, Songjiang Xian, Datong Xian, Pingding Xian, Xing Xian, Chongqing Xian, Xichong Xian, Zizhong Xian, Mozhugongka Xian, Xinyuan Xian, Guangnan Xian, Tonghai Xian, Xiangyun Xian, Fuyang Xian, Yongjia Xian 